\title{
Changes in Streamflow Dynamics in the Rhine Basin under Three High-Resolution Regional Climate Scenarios
}

\author{
Ruud Hurkmans, Wilco Terink, Remko Uijlenhoet, and Paul Torfs \\ Hydrology and Quantitative Water Management Group, Wageningen University, Wageningen, Netherlands \\ DANIELA JACOB \\ Max Planck Institut für Meteorologie, Hamburg, Germany \\ Peter A. Troch \\ Department of Hydrology and Water Resources, The University of Arizona, Tucson, Arizona
}

(Manuscript received 2 February 2009, in final form 21 August 2009)

\begin{abstract}
Because of global warming, the hydrologic behavior of the Rhine basin is expected to shift from a combined snowmelt- and rainfall-driven regime to a more rainfall-dominated regime. Previous impact assessments have indicated that this leads, on average, to increasing streamflow by $\sim 30 \%$ in winter and spring and decreasing streamflow by a similar value in summer. In this study, high-resolution $\left(0.088^{\circ}\right)$ regional climate scenarios conducted with the regional climate model REMO (REgional MOdel) for the Rhine basin are used to force a macroscale hydrological model. These climate scenarios are based on model output from the ECHAM5Max Planck Institute Ocean Model (MPI-OM) global climate model, which is in turn forced by three Special Report on Emissions Scenarios (SRES) emission scenarios: A2, A1B, and B1. The Variable Infiltration Capacity model (VIC; version 4.0.5) is used to examine changes in streamflow at various locations throughout the Rhine basin. Average streamflow, peak flows, low flows, and several water balance terms are evaluated for both the first and second half of the twenty-first century. The results reveal a distinct contrast between those periods. The first half is dominated by increased precipitation, causing increased streamflow throughout the year. During the second half of the century, a streamflow increase in winter/spring and a decrease in summer is found, similar to previous studies. This is caused by 1) temperature and evapotranspiration, which are considerably higher during the second half of the century; 2) decreased precipitation in summer; and 3) an earlier start of the snowmelt season. Magnitudes of peak flows increase during both periods, and the magnitudes of streamflow droughts increase only during the second half of the century.
\end{abstract}

\section{Introduction}

According to the latest Intergovernmental Panel on Climate Change (IPCC) assessment report (Adger et al. 2007), all currently available global climate models agree on an increase in global mean temperature of $1.1^{\circ}-6.4^{\circ} \mathrm{C}$ over the twenty-first century. Associated with this global warming, the hydrological cycle is expected to intensify, causing precipitation to fall in more extreme events (Trenberth et al. 2003). In addition, higher air tem-

Corresponding author address: Ruud Hurkmans, Hydrology and Quantitative Water Management Group, Wageningen University, P.O. Box 47, 6700 AA, Wageningen, Netherlands.

E-mail: ruud.hurkmans@wur.nl peratures will cause more precipitation to fall as rain instead of snow and will cause the snowmelt season to start earlier in the year (Barnett et al. 2005). As far as the Rhine basin is concerned, this amounts to an increase in temperature of $1.0^{\circ}-2.4^{\circ} \mathrm{C}$ by 2050 , causing the hydrological regime of the Rhine to shift from a combined rainfall- and snowmelt-driven system to a more rainfalldominated system (Barnett et al. 2005; Adger et al. 2007).

The Rhine basin is densely populated and heavily industrialized, and the river Rhine has the highest traffic density in Europe as an inland waterway. Its water is used for many purposes, for example, agriculture, industry, domestic water supply, and (hydro-) power generation (Kwadijk and Rotmans 1995; Middelkoop et al. 2001). Because of all the economic value that is 
concentrated in the basin, it is very vulnerable to hydrologic extremes, both floods and droughts (Kleinn et al. 2005). It is therefore not surprising that many climate change impact assessments have been carried out for the Rhine basin in recent years (e.g., Graham et al. 2007; Kwadijk and Middelkoop 1994; Kwadijk and Rotmans 1995; Lenderink et al. 2007; Middelkoop et al. 2001; Pfister et al. 2004; Shabalova et al. 2003; Zierl and Bugmann 2005). Most of these studies are based on climate model output, which are based on scenarios describing greenhouse gas emissions. Emission scenarios range from a simple doubling of $\mathrm{CO}_{2}$ concentrations (e.g., Middelkoop et al. 2001) or a gradual increase of $\mathrm{CO}_{2}$ (e.g., $1 \% \mathrm{yr}^{-1}$ in Shabalova et al. 2003) to the more complex scenarios developed by IPCC in the Special Report on Emissions Scenarios (SRES; Nakićenović and Swart 2000). SRES scenarios are based on several alternative developments of energy technology and contain not only $\mathrm{CO}_{2}$ but also other greenhouse gases and aerosols. Because the spatial resolution of global climate models (GCM) is generally too low for hydrological applications $(>100 \mathrm{~km})$, downscaling occurs either by statistical methods [as was done, e.g., by Kwadijk and Middelkoop (1994); Kwadijk and Rotmans (1995)] or by nesting a regional climate model (RCM) in the GCM over the domain of interest (e.g., Graham et al. 2007; Shabalova et al. 2003; Middelkoop et al. 2001; Kleinn et al. 2005). The downscaled climate data are then fed to some hydrological model to obtain river discharges. Because RCMs often give different results (e.g., van den Hurk et al. 2005), often multiple RCMs are used. For example, Graham et al. (2007) used results from all RCMs that were compared in the Prediction of Regional Scenarios and Uncertainties for Defining European Climate Change Risks and Effects (PRUDENCE) project (Christensen et al. 2007) to investigate the effects of climate change on Rhine River discharge. All the assessments mentioned above qualitatively agree in their results. More discharge is projected in winter and spring because of increased precipitation and snowmelt $(+30 \%$ according to Lenderink et al. 2007 and Shabalova et al. 2003), and less discharge is projected in summer because of increased evapotranspiration, less snow buffering, and decreased precipitation $(-30 \%$ to $-40 \%$ according to the same studies).

In the studies described above, most of the employed regional climate scenarios have spatial resolutions of 25$50 \mathrm{~km}$. By means of a second downscaling step, higher spatial resolutions can be obtained. From the Max Planck Institut für Meteorologie (MPI-M) in Hamburg, Germany, climate scenarios are available for the Rhine basin at a spatial resolution of $0.088^{\circ}(\sim 10 \mathrm{~km})$. These scenarios are based on the GCM ECHAM5-Max Planck
Institute Ocean Model (MPI-OM) and downscaled in two steps by the regional climate model REMO (Jacob 2001). To capture extreme precipitation events, and thus also extreme peak flow events, a high spatial resolution is important because extreme precipitation is usually convective in nature and its spatial extent relatively small. Moreover, as part of the catchment is very mountainous, orography is relatively complex and a high model resolution allows more of this complexity to be resolved explicitly. An additional advantage of the climate scenarios used in this study is the fact that they are transient, spanning the entire twenty-first century. The studies that were mentioned above typically used a time slice of $30 \mathrm{yr}$, often the period 2071-2100.

In this study, we employ three high-resolution climate change scenarios, according to three SRES scenarios: $\mathrm{B} 1, \mathrm{~A} 1 \mathrm{~B}$, and $\mathrm{A} 2$. We compare the scenarios with results of a reference model run spanning the period 1950-2000. All atmospheric time series are corrected for their model bias based on observations of precipitation and temperature (section 3a). As a macroscale hydrological model, we use the Variable Infiltration Capacity model (VIC; Liang et al. 1994). This model was applied to the Rhine basin at a spatial resolution of $0.05^{\circ}(\sim 5.5 \mathrm{~km})$, as described by Hurkmans et al. (2008). Compared to other models that are typically used for climate change impact studies and that are generally more simple, VIC has the advantages that 1 ) its parameterization of evapotranspiration is physically based; 2) it has a detailed description of snow accumulation and melt processes; and 3) subgrid variability of land use, elevation, and infiltration is taken into account. For these reasons, VIC was found to be less sensitive to parameter settings than the more simple water balance models mentioned above (Hurkmans et al. 2008). This is an important advantage because it is questionable whether conceptual model parameters determined under current climate conditions will be valid throughout the twenty-first century under a changing climate. From the model results, we investigate the effect of climate change on average and extreme streamflow, both in terms of peak flows and streamflow droughts. By analyzing streamflow at several locations throughout the river basin and the distributed model results, the spatial pattern of the effects of climate changes is investigated. Finally, changes in various components of the water balance such as evapotranspiration, snowmelt, and baseflow are analyzed.

\section{Data and model}

\section{a. Study area}

The Rhine basin is a major river in western Europe. It originates in the Swiss Alps and drains portions of 


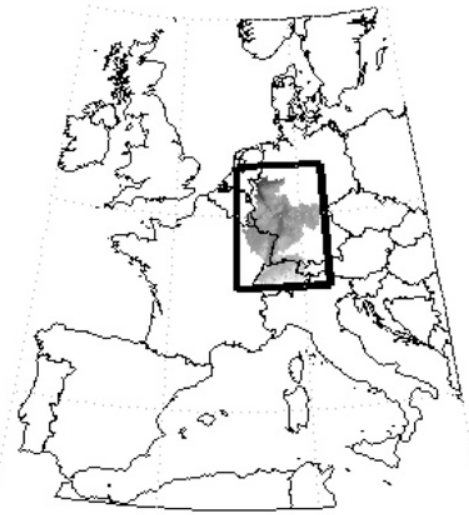

Altitude [m a.s.I.]

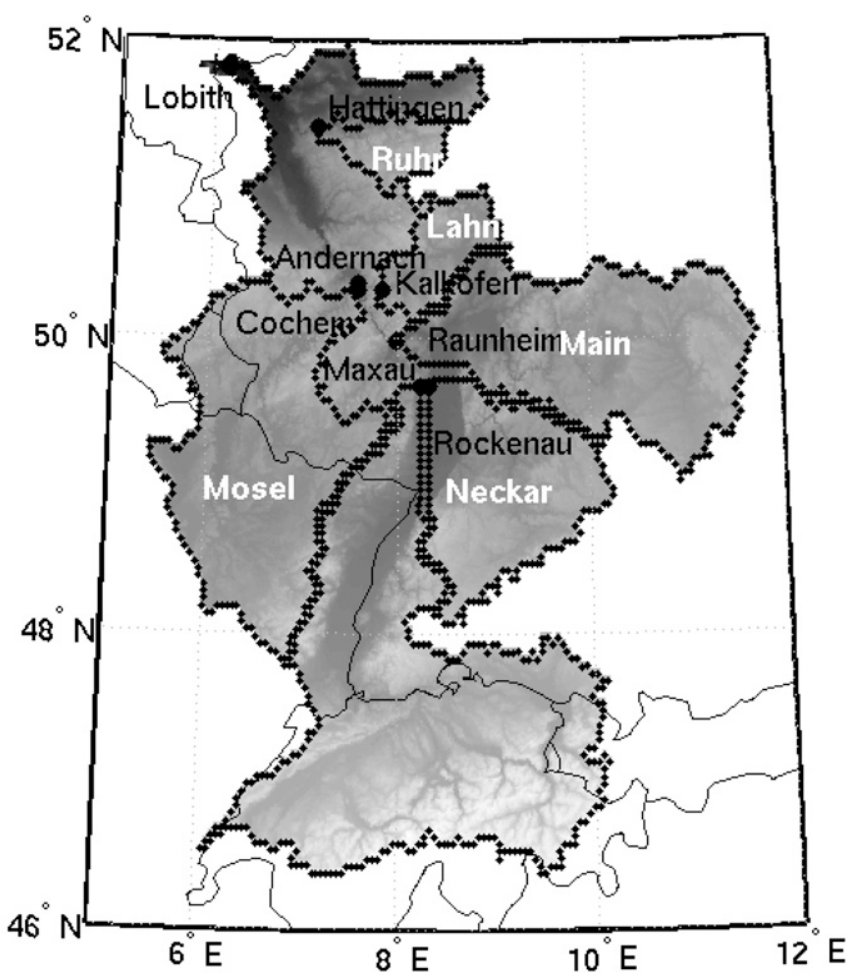

FIG. 1. (left) Location of the Rhine basin and (right) elevations in the basin. The outline of the basin and the subbasins represent the discretization of the basin in VIC (at a resolution of $0.05^{\circ}$ ). Source: Hurkmans et al. (2009).

Switzerland, Germany, France, and the Netherlands before draining in the North Sea. The total area covered is about $185000 \mathrm{~km}^{2}$. After crossing the German-Dutch border at Lobith, the river splits into three branches. Therefore, we only take into account the area upstream of Lobith (Fig. 1).

\section{b. Hydrological model}

The VIC model (Liang et al. 1994) is a distributed, macroscale hydrological model. It is developed to provide land surface boundary conditions for climate models and therefore solves evapotranspiration and the associated turbulent fluxes in a physically based way. The coupled water and energy balances are solved, in combination with the Penman-Monteith equation (Penman 1948; Monteith 1965), to calculate evapotranspiration. Subgrid variability in land use and elevation is accounted for by dividing each grid cell into tiles based on fractional areal coverage. Subgrid variability of topography is accounted for by means of an exponential relation between the fraction of the grid cell that is saturated and the infiltration capacity. The soil column is divided in three soil layers. Drainage from the surface to the lowest layer is gravity-driven and downward only. Baseflow depends on the soil moisture content of the lowest soil layer through a function that consists of a linear and a nonlinear segment. Routing of baseflow and surface runoff occurs through a simple algorithm developed by Lohmann et al. (1996), which was applied in combination with VIC before (e.g., Lohmann et al. 1998a,b). The VIC model has been used in previous studies as a land surface parameterization in climate models (e.g., Lohmann et al. 1998c; Pitman et al. 1999; Liang et al. 1998) but also for hydrological purposes. For example, Hamlet et al. (2007) used the model for climate variability impact assessments and Matheussen et al. (2000) and Hurkmans et al. (2009) investigated land use changes using VIC.

The VIC model was applied to the Rhine basin in a previous study (Hurkmans et al. 2008) at a spatial resolution of $0.05^{\circ}$ and a temporal resolution of $3 \mathrm{~h}$. Two modifications of the VIC model that were introduced in a recent study dealing with land use changes (Hurkmans et al. 2009) are used in this study as well. First, in sparsely vegetated areas bare soil evaporation is allowed to occur at the same time as transpiration and canopy evaporation. Second, a parameter is introduced in urban areas to increase the amount of surface runoff relative to baseflow. For more details about these modifications, we refer to Hurkmans et al. (2009). Atmospheric forcing for the model is described in section 2c. Land use data were obtained from the Pan-European Land Cover 
TABLE 1. Overview of atmospheric datasets used in this study.

\begin{tabular}{llccr}
\hline \hline \multicolumn{1}{c}{ Dataset } & Driving model & Spatial resolution & Time resolution & Period \\
\hline Validation & ECMWF & 0.088 & Hourly & $1979-2003$ \\
Reference & ECHAM5-MPI-OM & 0.088 & Hourly & $1950-2000$ \\
Scenarios & ECHAM5-MPI-OM & 0.088 & Hourly & $2001-2100$ \\
Observations & - & Subbasin & Daily & $1961-95$ \\
\hline
\end{tabular}

Monitoring (PELCOM) project (Mücher et al. 2000) at a spatial resolution of $1 \mathrm{~km}$, and soil data are taken from the global Food and Agriculture Organization (FAO) dataset described by Reynolds et al. (2000). Based on percentages of sand and clay from this dataset, soil textures are classified and the default parameters from the VIC Web site (http://www.hydro.washington.edu/ Lettenmaier/Models/VIC/) are assigned to each class.

\section{c. Atmospheric data}

All atmospheric datasets that are used in this study are model output from the regional climate model REMO (Jacob 2001) as provided by MPI-M in Hamburg, Germany. A validation dataset, a reference dataset, and three scenarios datasets were available. The main characteristics of all datasets are shown in Table 1 , and the way they are used in this study is shown schematically in Fig. 2. The validation dataset is an extended version of the atmospheric dataset that was used in Hurkmans et al. (2008) and Hurkmans et al. (2009). It is based on the global 15-yr European Centre for Medium-Range Weather Forecasts (ECMWF) Re-Analysis (ERA-15) reanalysis dataset (http://www.ecmf.int; 1979-93), extended up to 2003 using operational ECMWF analysis data. Because the ERA data are (partly) based on observations, these data can be used to calibrate the hydrological model, as was done in Hurkmans et al. (2008). The reference dataset is based on a REMO model run driven by the general circulation model ECHAM5-MPI-OM, as are the three scenario datasets. Because the reference dataset is not constrained by observations, it only resembles the current climate in a statistical sense. It cannot, therefore, be used for hydrological model calibration. Because it is based on the same models as the scenarios, it can be compared with the scenarios to obtain a climate change signal. This is not the case for the validation dataset because it is based on a different driving model (i.e., ERA data).

The spatial resolutions of both ERA and ECHAM5MPI-OM data are too low for hydrological applications

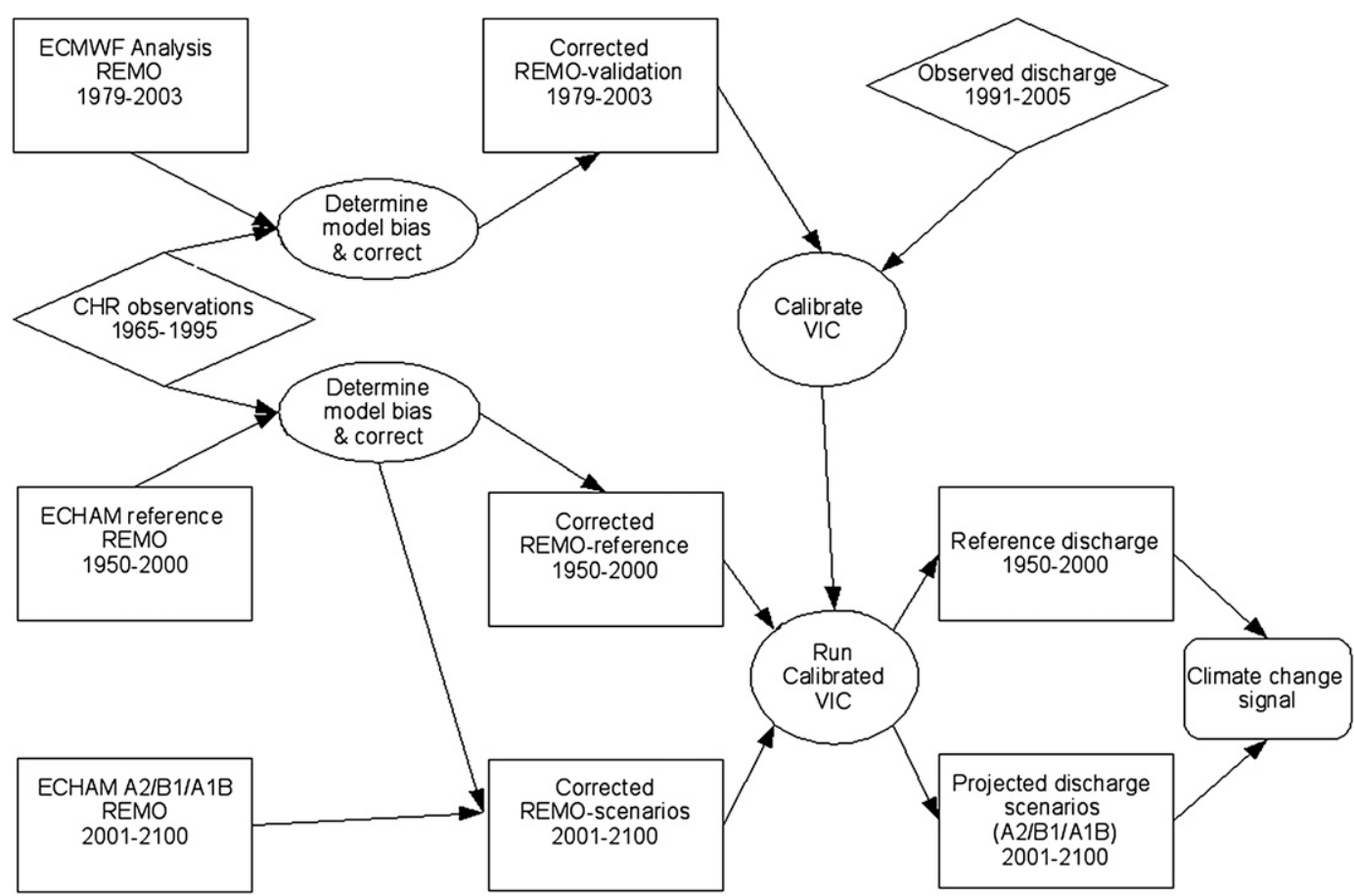

FIG. 2. Schematic representation of all datasets used in this study and how they are used. 
( $>100 \mathrm{~km})$. They are, therefore, dynamically downscaled using the REMO model in two steps. First, intermediate REMO output with a resolution of $0.44^{\circ}$ (about $50 \mathrm{~km}$ ) is obtained, which is downscaled using a second step to $0.088^{\circ}$ [about $10 \mathrm{~km}$; Jacob et al. (2008) and S. Kotlarski 2008, personal communication; MPI-M].

Both driving "models," ERA data and ECHAM5MPI-OM, have structural modeling errors compared with observations. Prior to using the data, this model bias needs to be corrected for using observations. Interpolated observations were available over the Rhine basin (Sprokkereef 2001) for this purpose. Because the spatial and temporal resolutions of these observations are too low, they cannot be used to force the VIC model. Therefore, we use the validation and reference datasets described above to represent the current climate conditions. The bias corrections are described in detail in section 3a. Because the three scenario datasets are based on the same modeling chain as the reference dataset, we assume that the model bias is similar for both the reference dataset and the scenarios and apply the same correction to both.

The three scenarios are based on three different $\mathrm{CO}_{2}$ emission scenarios as defined by the IPCC in the SRES (Nakićenović and Swart 2000): the A2, A1B, and B1 scenarios. Each of those scenarios is based on a storyline of energy and technology development. The A2 scenario refers to a world with continuously growing population and very regionally oriented economic growth. A1B refers to a globalized, very rapidly growing economy with fast introduction of new technologies that are balanced between fossil fuel intensive and sustainable and clean. Population in A1B grows rapidly until the middle of the century and declines thereafter. B1, finally, refers to a globalized, rapidly growing population but with changes in economic structure with an environmental emphasis and fast introduction of clean and efficient technologies. For more details about these storylines, we refer to Nakićenović and Swart (2000).

\section{Methodology}

\section{a. Bias correction}

A problem with the use of RCM output is the fact that simulated precipitation and temperature differ systematically from observed values (Christensen et al. 2008). These biases can vary among RCMs and are also geographically dependent (Jacob et al. 2007), and, to obtain realistic streamflow simulations in the present climate, they should be corrected (Lenderink et al. 2007). Different methods exist to correct for these biases. For example, Lenderink et al. (2007) used a spatially and seasonally varying correction factor, and Hay et al. (2002) used the gamma distribution to match observed and simulated precipitation values. In this study, we use a relatively simple method that was applied to the Meuse basin by Leander and Buishand (2007). In addition, Shabalova et al. (2003) applied it to the Rhine basin to obtain a plausible climate scenario. An advantage of this method is that not only the mean but also the temporal variability is corrected. The method corrects precipitation and temperature separately and leaves other input variables for VIC (i.e., radiation, humidity, wind speed, and air pressure) unaffected. Because no observations are available for these variables at this scale and resolution, it is not possible to correct for them. Moreover, the effects on the resulting streamflow induced by errors occurring in these variables are relatively small compared to biases in precipitation and temperature. Observed precipitation and temperature for the period 1961-95 are available on a daily basis for each of 134 subcatchments in the Rhine basin (Sprokkereef 2001). Therefore, and because the model bias was found to vary spatially (in accordance with Leander and Buishand 2007 and Lenderink et al. 2007), the bias correction is applied to daily average temperature and daily accumulated precipitation for each subbasin individually.

Because the reference dataset and validation datasets (Table 1) are based on different models, a bias correction is applied to both datasets separately. For both corrections, the maximum period of overlap between data and observations is used to estimate the correction parameters. For the validation dataset this period is 1979-95, whereas for the reference dataset it is 1961-95. For both precipitation and temperature, a 5-day climatology is derived from observations and model output by calculating the average and standard deviation over all available years, that is, $17 \mathrm{yr}$ for the validation and $35 \mathrm{yr}$ for the reference dataset. A window of 30 days before and 30 days after the considered 5-day period is used to calculate the "smoothed" average and standard deviation. The average and standard deviation are thus calculated over $65 \times 17$ (validation dataset) or $65 \times 35$ (reference dataset) data points. The correction is applied separately for each of the 73 five-day periods in the resulting climatology.

Precipitation is corrected according to a nonlinear function (Leander and Buishand 2007):

$$
P^{*}=a P^{b},
$$

where $P$ is the uncorrected precipitation, $P^{*}$ is the corrected precipitation, and $a$ and $b$ are two parameters. First, $b$ is fitted for the coefficient of variation $(\mathrm{CV})$ of the modeled precipitation to match the $\mathrm{CV}$ of the 

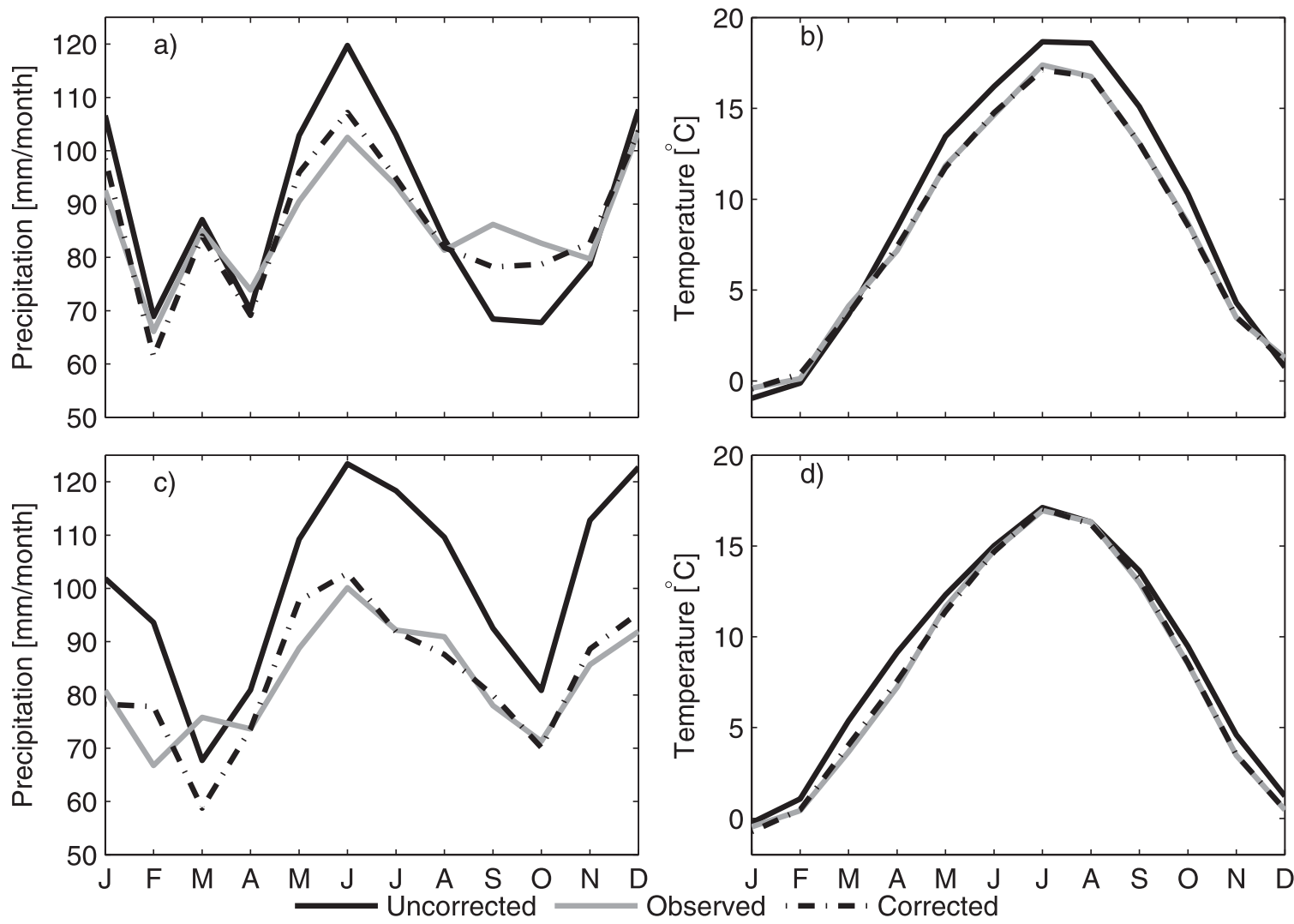

FIG. 3. Results of the bias corrections for the (a),(b) validation and (c),(d) reference datasets. Monthly averaged precipitation [(a) and (c)] and temperature [(b) and (d)], both weighted by subbasin area, are shown for observed, uncorrected, and corrected precipitation and temperature.

observed precipitation. Second, $a$ is fitted such that the average modeled precipitation fits the average of the observed precipitation (using the value of $b$ obtained in the first step).

The correction of temperature is done in a linear way, based on the mean and standard deviation. For each subbasin, the corrected daily temperature $T_{\text {mod }}^{*}$ is calculated as

$T_{\text {mod }}^{*}=\bar{T}_{\text {obs }}+\frac{\sigma\left(T_{\text {obs }}\right)}{\sigma\left(T_{\text {basin }}\right)}\left(T_{\text {mod }}-\bar{T}_{\text {obs }}\right)+\left(\bar{T}_{\text {obs }}-\bar{T}_{\text {basin }}\right)$,

where $T_{\text {mod }}$ is the uncorrected daily modeled temperature, $T_{\text {obs }}$ is the observed daily average temperature for a subbasin, and $T_{\text {basin }}$ is the modeled subbasin average temperature. In Eq. (2) an overbar denotes the average over the considered period (1979-95 for the validation dataset; 1961-95 for the reference dataset) and $\sigma$ denotes the standard deviation.

Results of the bias correction of the validation dataset, as well as the reference dataset, can be found in Figs. 3 and 4. Figure 3 shows climatologies of corrected and uncorrected precipitation and temperatures for both the validation and the reference dataset. It appears that the correction works very well in terms of monthly averages. Especially for temperature, corrected values almost exactly match the observed ones. The mean absolute error (MAE) decreased from $1.15^{\circ}$ to $0.15^{\circ} \mathrm{C}$ for the validation dataset and from $0.76^{\circ}$ to $0.16^{\circ} \mathrm{C}$ for the reference dataset. For precipitation, the results are not as good as for temperature, but still the monthly means were improved significantly: for the validation dataset the MAE decreased from 8.5 to $3.6 \mathrm{~mm} \mathrm{month}{ }^{-1}$, and for the reference dataset the MAE decreased from 19.5 to $4.6 \mathrm{~mm}$ month $^{-1}$. Figure 4 shows spatial patterns of the difference between modeled (corrected and uncorrected) and observed precipitation and temperature. Differences between uncorrected and observed precipitation are sometimes very large; especially in the Alps differences of more than $500 \mathrm{~mm} \mathrm{yr}^{-1}$ exist. For all subbasins, however, the correction performs well: the spatial MAE (weighted to area, for temporal averages) drops from 161 to $9 \mathrm{~mm} \mathrm{yr}^{-1}$ for the validation dataset and from 276 to $12 \mathrm{~mm} \mathrm{yr}^{-1}$ for the reference dataset. For temperature, the weighted MAE is also reduced significantly: for the validation dataset from 
Val. uncorrected

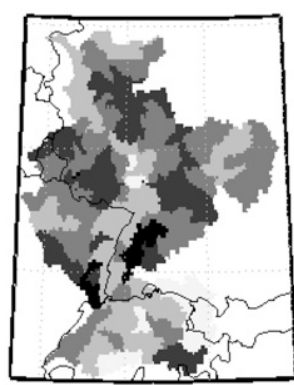

$\Delta \mathrm{P}[\mathrm{mm} /$ year $]$

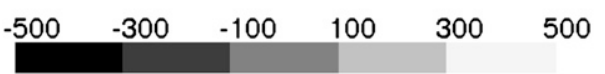

Ref. uncorrected

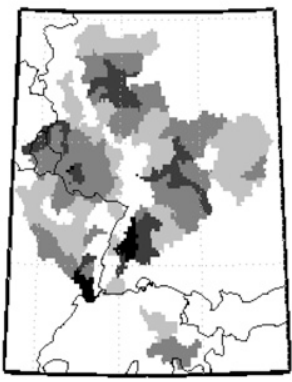

Val. corrected

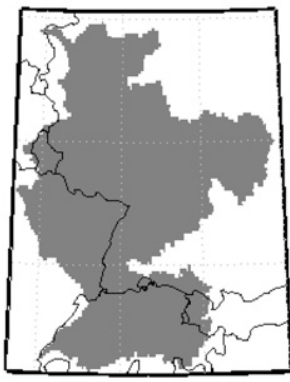

Val. uncorrected

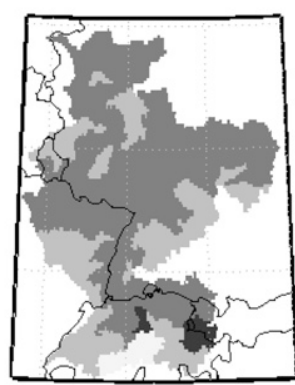

Val. corrected

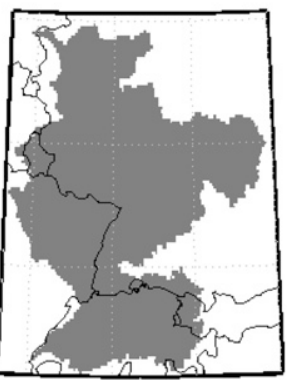

$\Delta \mathrm{T}\left[{ }^{\circ} \mathrm{C}\right]$

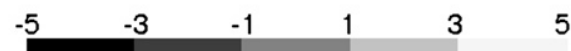

Ref. uncorrected

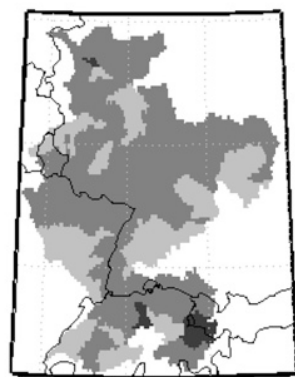

Ref. corrected

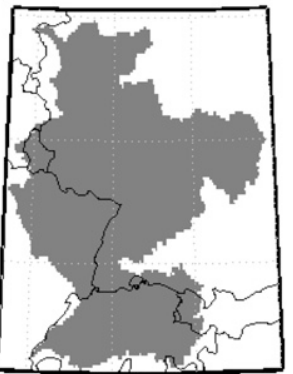

FIG. 4. Results of the bias corrections in terms of spatial patterns. Each map shows the difference between corrected or uncorrected data vs observations. Differences in mean annual temperature and mean cumulative precipitation are shown for both the (top) validation and (bottom) reference datasets. Positive values indicate an overestimation with respect to the observations.

$0.91^{\circ}$ to $0.06^{\circ} \mathrm{C}$ and for the reference dataset from $0.85^{\circ}$ to $0.06^{\circ} \mathrm{C}$. Additional validation analyses (Terink et al. 2008) showed that, apart from these numbers-also other statistics, such as the extreme values (low exceedance probabilities) - the lag-1 autocorrelation and the number of wet days in the corrected datasets improved with respect to the uncorrected ones. An important statistic for extreme peak flows for the Rhine basin is that of 10-day precipitation sums (e.g., Shabalova et al. 2003). Terink et al. (2008) analyzed those as well and found for the reference dataset an improvement of extreme 10-day precipitation sums in the corrected data compared to the uncorrected data. For the validation dataset, this improvement is smaller.

\section{b. Model calibration}

The bias-corrected validation dataset is used to calibrate VIC. Because the calibration process is computationally quite demanding, we calibrated the model on a relatively short period: 1994-97. For each simulation, 1993 is used to initialize the model. The remainder of the validation dataset (1998-2003) is used to validate the model. The model was calibrated in a similar way as described in Hurkmans et al. (2008), using 5 calibration parameters and a numerically efficient algorithm, the downhill-Simplex algorithm (Nelder and Mead 1965), to optimize them simultaneously. The Nash-Sutcliffe model efficiency (Nash and Sutcliffe 1970) was used as objective function. A difference with the application described in Hurkmans et al. (2008) is the fact that, in this study, the model was calibrated for each of seven zones separately, including five of the largest tributaries. These zones are shown in Fig. 1. Calibration and validation results for the entire basin and the main tributaries are shown in Table 2.

From Table 2 it appears that, especially for mountainous areas such as the Rhine upstream of Maxau and the Neckar, performance indicators are relatively low. This can have several reasons: first, the model was forced by REMO model output, as was discussed previously. Differences between observations and this modeled data are at times quite large, as was also pointed out by Hurkmans et al. (2008), who compared the datasets extensively. Even though the structural error or bias was largely removed by the bias correction (see section $2 \mathrm{a}$ ), the variation over time was not changed and significant 
TABLE 2. Characteristics of observed streamflow and calibration and validation results for five of the main tributaries of the Rhine (Ruhr, Lahn, Main, Mosel, and Neckar) and three locations along the main branch of the Rhine: Maxau, Andernach, and Lobith. Mean, maximum, and mean annual maximum $\left(Q_{\text {mam }}\right)$ streamflow are all calculated for the period 1990-2005 (the extent of the database that is available). For the calibration period (1994-97) and the validation period (1998-2003), the correlation coefficient ( $\rho$ ), Nash-Sutcliffe modeling efficiency (E), and the relative volume error (RVE) are shown.

\begin{tabular}{|c|c|c|c|c|c|c|c|c|c|c|}
\hline \multirow[b]{2}{*}{$\begin{array}{c}\text { Subcatchment } \\
-\end{array}$} & \multirow[b]{2}{*}{$\begin{array}{c}\text { Station } \\
-\end{array}$} & \multicolumn{3}{|c|}{ Observed } & \multicolumn{3}{|c|}{ Calibration } & \multicolumn{3}{|c|}{ Validation } \\
\hline & & $\underset{\left(\mathrm{m}^{3} \mathrm{~s}^{-1}\right)}{Q_{\text {mean }}}$ & $\underset{\left(\mathrm{m}^{3} \mathrm{~s}^{-1}\right)}{Q_{\max }}$ & $\underset{\left(\mathrm{m}^{3} \mathrm{~s}^{-1}\right)}{Q_{\mathrm{mam}}}$ & $\begin{array}{c}\rho \\
(-)\end{array}$ & $\begin{array}{c}E \\
(-)\end{array}$ & $\begin{array}{l}\text { RVE } \\
(\%)\end{array}$ & $\begin{array}{c}\rho \\
(-)\end{array}$ & $\begin{array}{c}\mathrm{E} \\
(-)\end{array}$ & $\begin{array}{l}\text { RVE } \\
(\%)\end{array}$ \\
\hline Ruhr & Hattingen & 72.6 & 867.0 & 579.4 & 0.58 & 0.22 & 34.57 & 0.61 & 0.30 & 27.58 \\
\hline Lahn & Kalkofen & 46.0 & 587.4 & 373.0 & 0.80 & 0.59 & -13.37 & 0.61 & 0.27 & -7.31 \\
\hline Main & Raunheim & 175.2 & 1990.8 & 1053.3 & 0.81 & 0.65 & -7.25 & 0.69 & 0.42 & -7.95 \\
\hline Mosel & Cochem & 338.6 & 4008.9 & 2492.3 & 0.71 & 0.49 & 1.21 & 0.69 & 0.37 & 12.02 \\
\hline Neckar & Rockenau & 142.6 & 2105.4 & 1326.0 & 0.54 & 0.07 & 23.14 & 0.61 & -0.15 & 35.84 \\
\hline Rhine & Maxau & 1278.3 & 4427.8 & 3269.5 & 0.59 & 0.10 & 11.20 & 0.50 & -0.81 & 26.82 \\
\hline Rhine & Andernach & 2076.0 & 10460.0 & 7274.3 & 0.75 & 0.55 & 5.03 & 0.62 & 0.17 & 15.72 \\
\hline Rhine & Lobith & 2239.9 & 11774.6 & 7655.3 & 0.81 & 0.59 & 11.69 & 0.70 & 0.22 & 19.77 \\
\hline
\end{tabular}

differences between observed and modeled precipitation time series persisted. Second, the complex topography in the mountainous areas complicates hydrological modeling because of the high amount of small-scale heterogeneity. Third, there are some large surface reservoirs present in the Alpine part, such as the Bodensee, which are not included in the model but can damp peaks in the hydrograph considerably.

\section{Results}

The calibrated VIC model is now used to simulate streamflow for the reference period and the three climate scenarios described in section $2 \mathrm{c}$ using the biascorrected atmospheric data. Figure 5 shows annual time series of the annual mean, minimum, and maximum streamflow at the basin outlet, Lobith. For the reference period and the A2 scenario the 10th and 90th percentiles are also shown. Thus, Fig. 5 shows in a qualitative manner the trends in average, minimum, and maximum streamflow during the twenty-first century for all scenarios and the reference period. A striking feature is the fact that there seems to be a decreasing trend both in minimum and maximum streamflow, particularly during the period 2052-2100. However, annual maxima are higher than they are during the reference period throughout the twenty-first century. From the simulated records, the years 1951 and 2001 are used to initialize the model for the reference period and the scenarios, respectively. To be able to compare three periods of equal length, 2051 is also discarded, yielding three periods spanning $49 \mathrm{yr}$ each. In sections $4 \mathrm{~b}$ and $4 \mathrm{~d}$ we investigate the differences between the periods $2002-50$ and $2052-2100$ on one hand, and 1952-2000 on the other hand, in more detail.

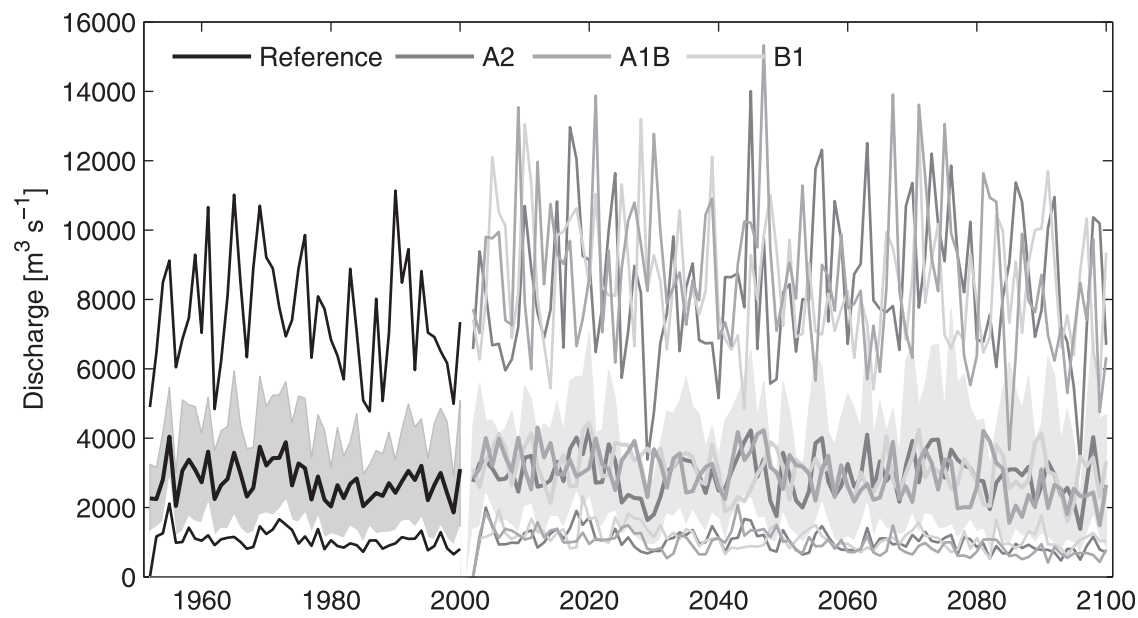

FIG. 5. Time series of annual mean (middle solid lines), maximum (upper lines), and minimum (lowest lines) daily streamflow at Lobith for all datasets. For the A2 scenario and the reference situation, the shaded area represents area between the 10th and 90th percentiles. 
DJF A2

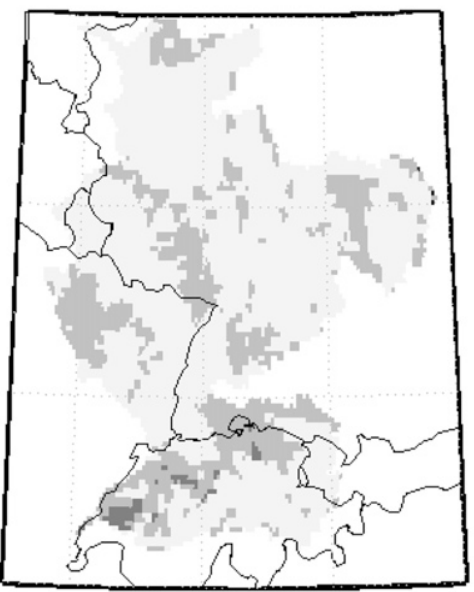

JJA A2

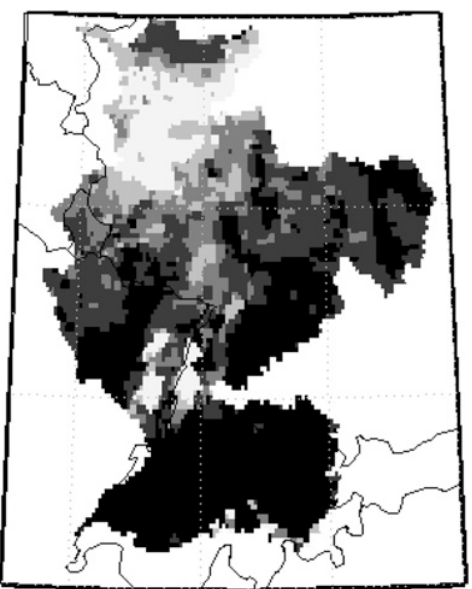

DJF A1B

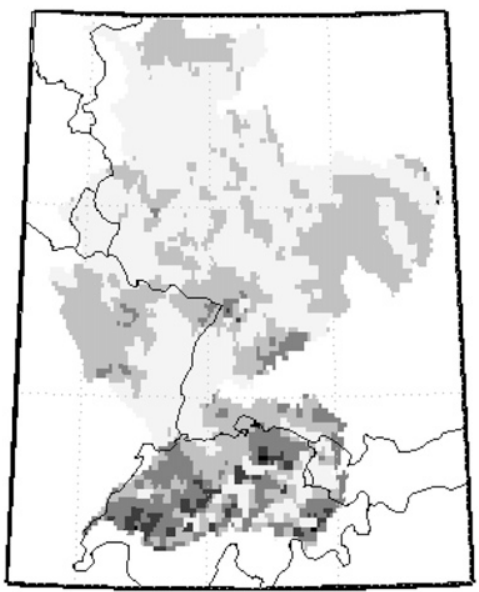

JJA A1B

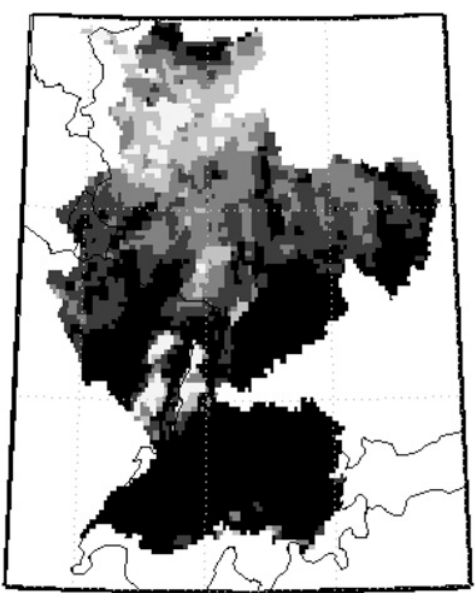

DJF B1

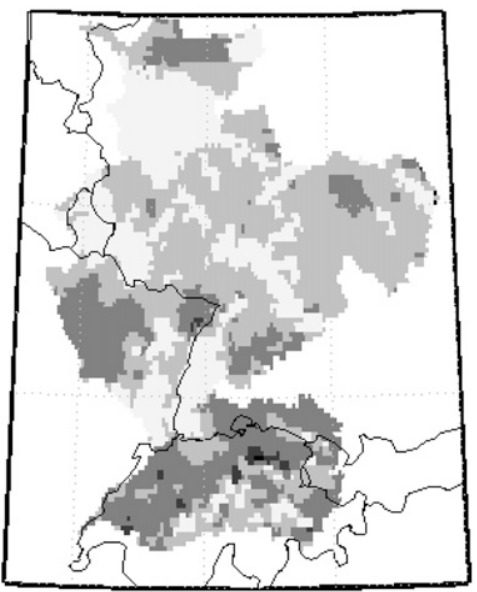

JJA B1

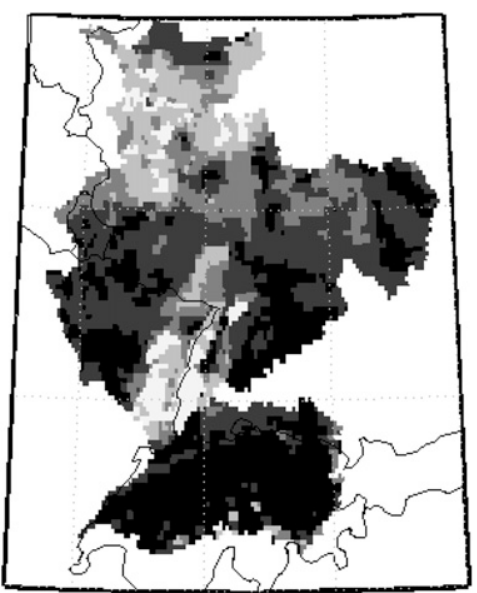

Seasonal average $\Delta$ Precipitation $\left[\mathrm{mm} \mathrm{month}^{-1}\right.$ ]

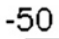

$-30$ $-10$ 10 30

FIG. 6. Difference in annual mean precipitation between three climate scenarios for the period 2052-2100 and the reference situation (1952-2000). Differences in (top) the winter season (DJF) and (bottom) the summer season (JJA). Positive values denote an increase compared to the reference situation.

\section{a. Spatial patterns of atmospheric variables}

To help interpret the changes in streamflow that are discussed later in this paper, spatial patterns of the differences in precipitation, evapotranspiration, and air temperature are plotted in Figs. 6, 7, and 8, respectively. Temperature and precipitation are used to force the VIC model and are bias corrected (section 3a), and evapotranspiration is simulated by the model. Only differences between the period 2052-2100 and the reference period are shown, both for the winter [DecemberFebruary (DJF)] and summer season [June-August (JJA)]
Figure 6 shows precipitation increases in winter and decreases in summer for all scenarios. The largest increases in precipitation during the winter season are found in the northern and western part, as well as the mountainous area of the Black Forest and the Vogues Mountains, located along the southern part of the Rhine Valley. The A2 scenario also shows increases in precipitation in the Alpine part and in some areas in the eastern Rhine basin, whereas the B1 scenario does not. The A1B scenario shows intermediate increases in those areas. In summer, the decrease in precipitation mainly occurs in the Alpine part of the basin, the Neckar subbasin, and the southern 
DJF A2

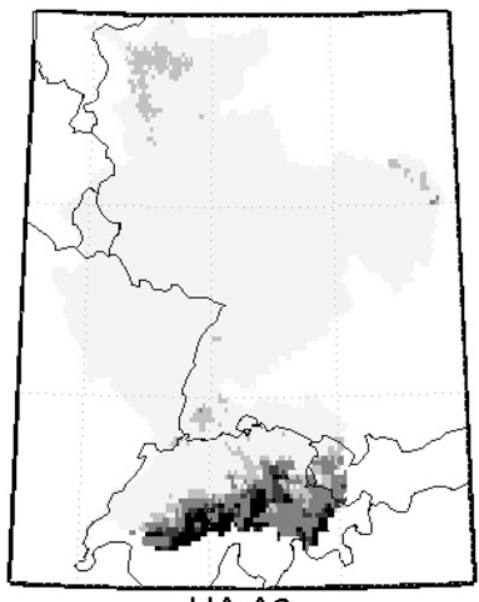

JJA A2

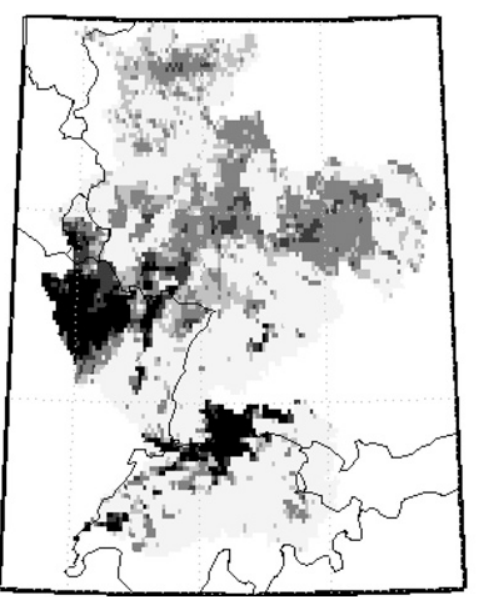

DJF A1B

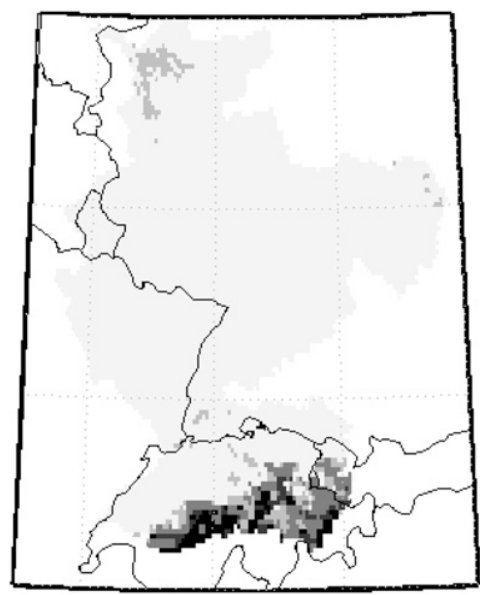

JJA A1B

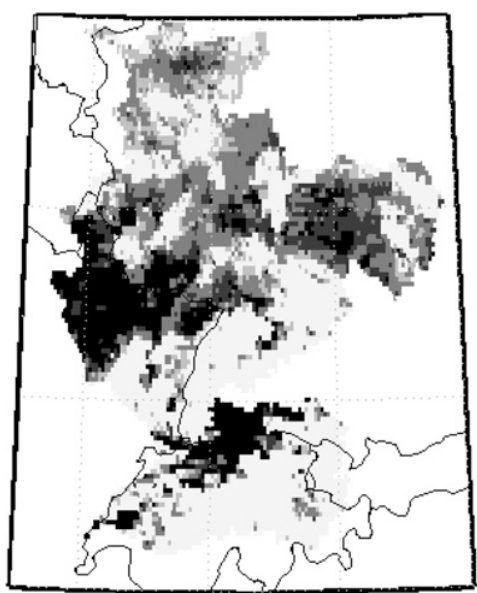

DJF B1

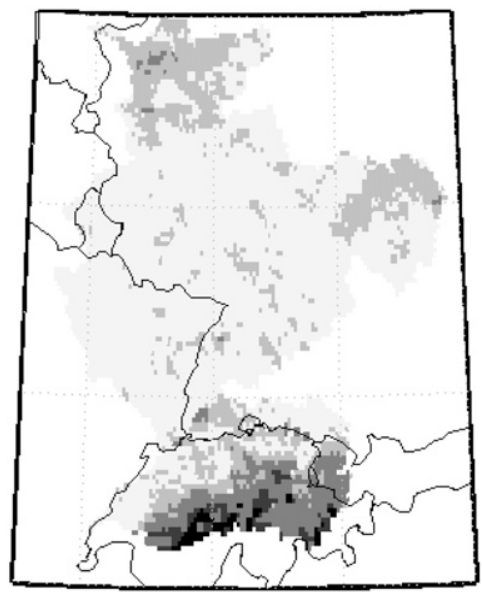

JJA B1

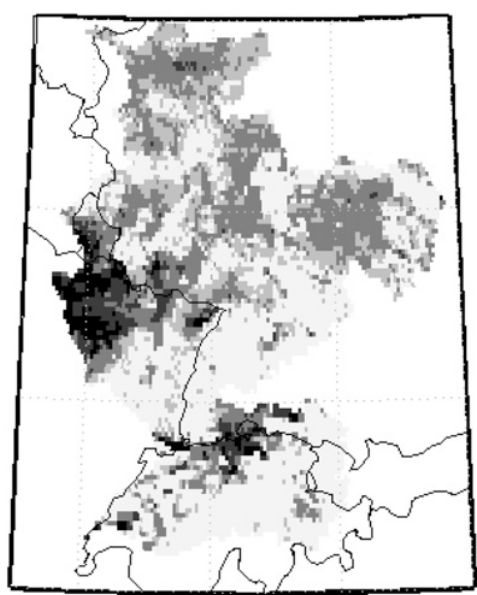

Seasonal average $\Delta$ Evapotranspiration $\left[\mathrm{mm} \mathrm{month}^{-1}\right.$ ]

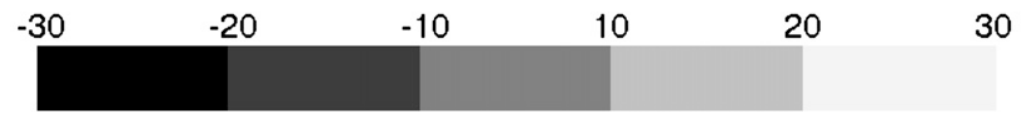

FIG. 7. As in Fig. 6, but for actual evapotranspiration.

part of the Mosel. The northern part, the Black Forest, and the Vogues area still show small increases in precipitation. Figure 6 shows the advantage of the employed high-resolution climate scenarios: (relatively) small-scale topographic features like the Black Forest and the Vogues Mountains generally do not show up in spatial analyses using a lower resolution (e.g., Shabalova et al. 2003). It should be noted that the spatial pattern of the applied precipitation is influenced by our bias correction. Because the correction was applied for each of 134 subbasins separately, the overall spatial pattern is "drawn" toward that of the observations to some extent (see Fig. 4). In addition, because the same exponent in Eq. (1) is applied to the reference dataset and the sce- narios, differences between those can be amplified or reduced locally.

The high spatial resolution of evapotranspiration as plotted in Fig. 7 allows for a detailed analysis of regional differences. Changes in actual evapotranspiration (Fig. 7) are quite homogeneous in space during the winter season: the entire basin, except the upper Alpine part, experiences increases in evapotranspiration of $8-20 \mathrm{~mm} \mathrm{month}{ }^{-1}$. In summer, however, there are large regional differences. Large parts of the western part (the Mosel area), as well as the eastern part (the Main) and a small area in northern Switzerland, show small decreases in evapotranspiration. Ideally, to confirm that these decreases are caused by water limitation, one would want to see a 
DJF A2

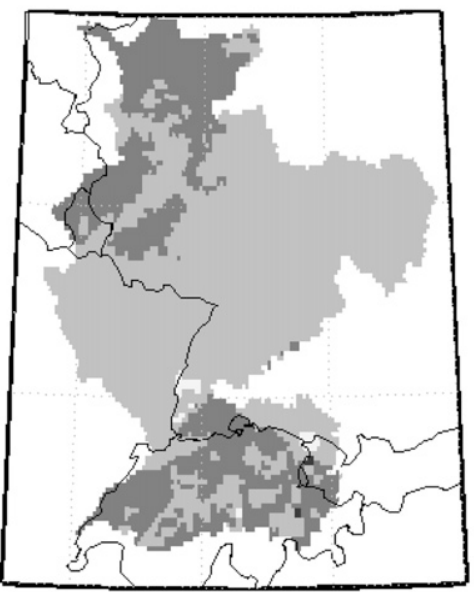

JJA A2

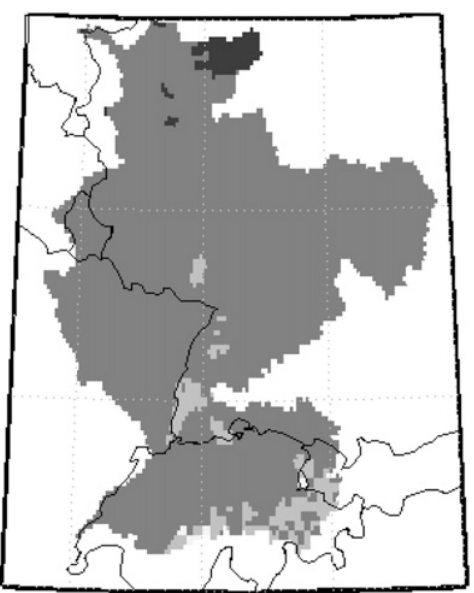

DJF A1B

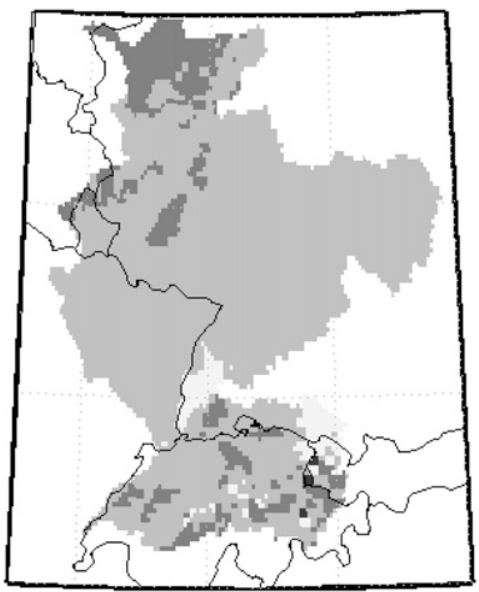

JJA A1B

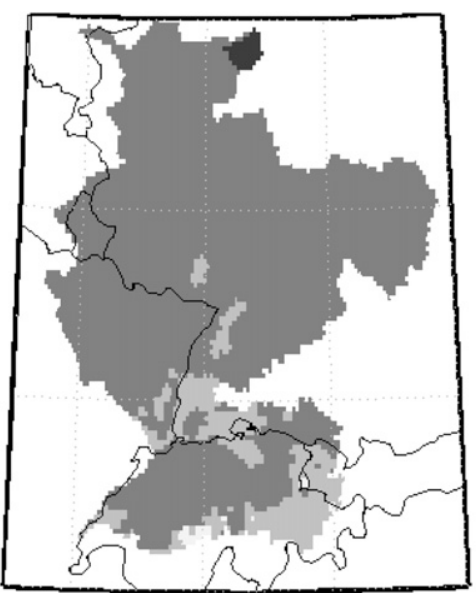

DJF B1

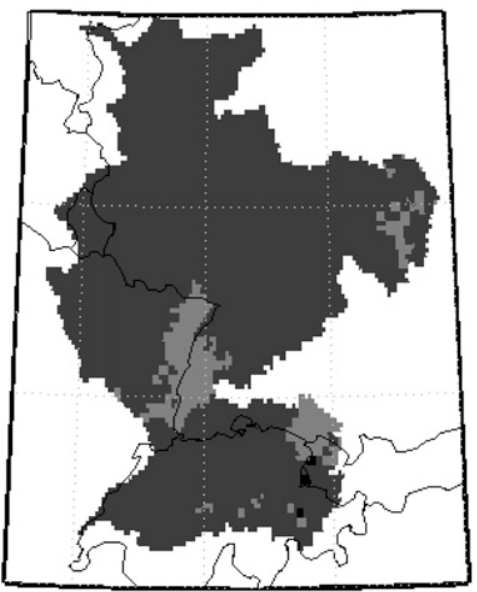

JJA B1

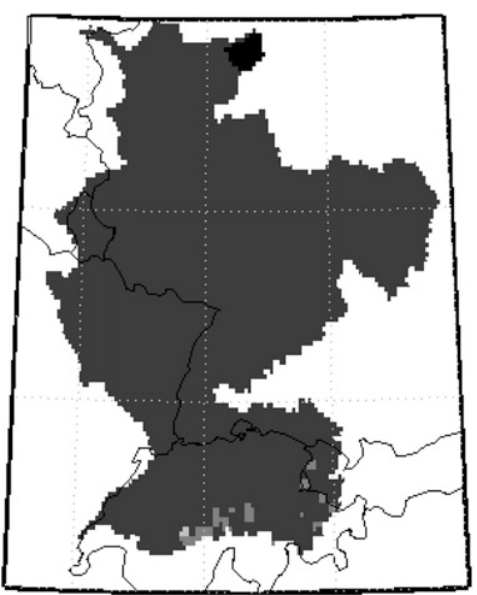

Seasonal average $\Delta$ Air temperature $\left[{ }^{\circ} \mathrm{C}\right]$

12 3 4 5 6

FIG. 8. As in Fig. 6, but for air temperature.

similar plot of the potential evapotranspiration. This, however, does not belong to the standard VIC model output. Because of the parameterizations for subgrid variability in the model (section $2 b$ ), it is not trivial to extract this information, therefore we used air temperature as a proxy for potential evapotranspiration (Fig. 8). Radiation would be another option to use as a proxy but we do not expect the spatial pattern of incoming radiation to be very different from that of air temperature. The spatial pattern for temperature also looks quite homogeneous for both seasons, albeit the warming is somewhat higher in the southern part, the valley of the upper Rhine, and the higher areas on either side. Assuming that potential evapotranspiration follows a sim- ilar spatial pattern as temperature, this suggests that the decreasing evapotranspiration values in summer could indeed be caused by water limitation. The latter is also indicated by results of Hagemann et al. (2009), who considered climate change simulations of REMO with about 50-km horizontal resolution.

\section{b. Mean streamflow}

Figure 9 shows the climatologies of relative differences in streamflow between each of the two future periods and the reference period, at four locations in the Rhine basin, representing a small (Ruhr) and a large (Main) tributary, the Alpine part (Maxau), and the entire basin (Lobith). The lower panel of Fig. 9 shows the 

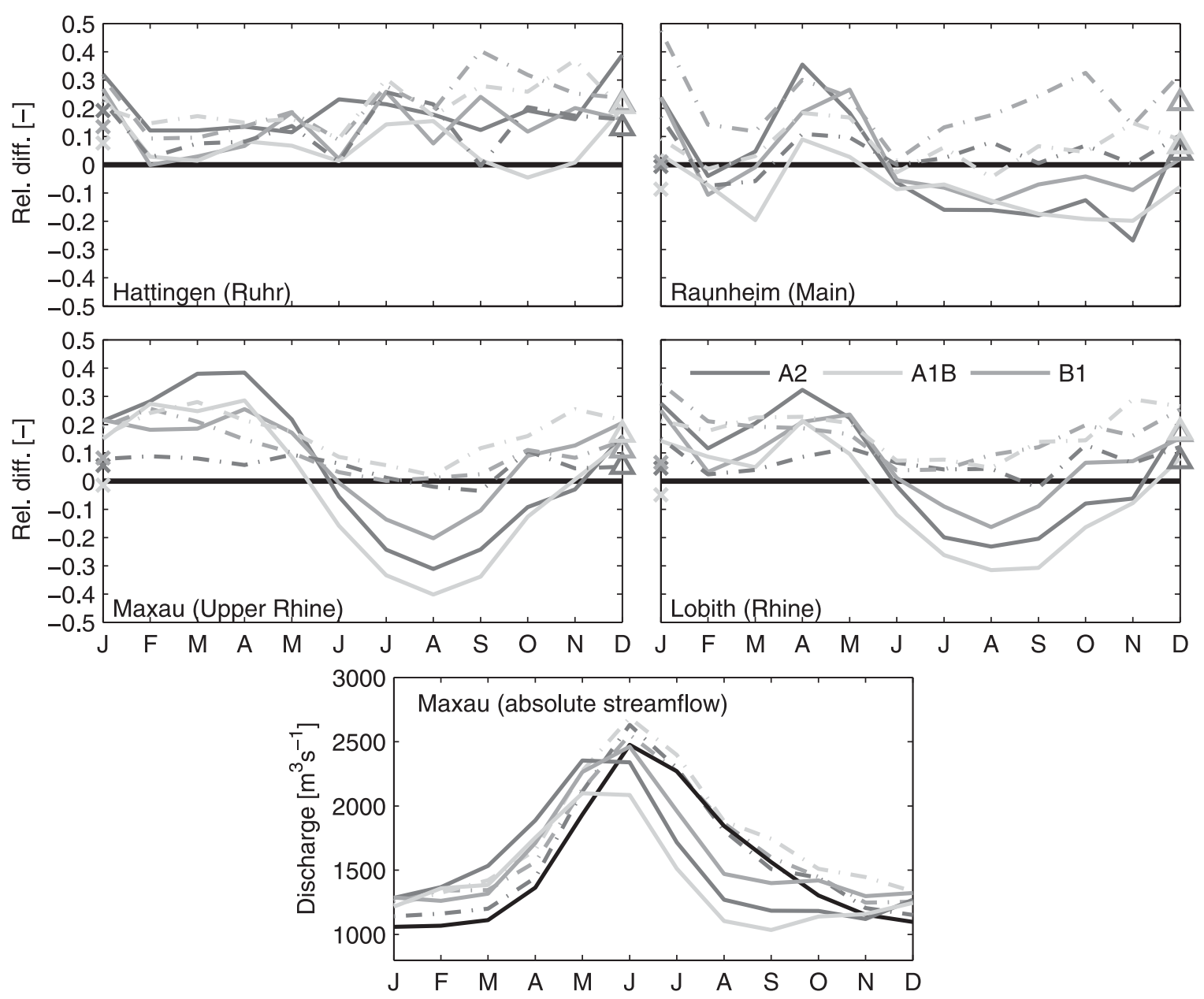

FIG. 9. Climatologies of the difference in streamflow between three climate scenarios (A2, A1B, and B1) and the reference situation at four locations in the Rhine basin: Hattingen (Ruhr), Raunheim (Main), Maxau (upper Rhine), and Lobith (entire Rhine). Overall averages are indicated with crosses and triangles at the y axes. Dash-dotted lines and triangles indicate changes between the period 2002-50 and the reference period, whereas solid lines and crosses indicate changes between the period 2052-2100 and the reference period. Positive values denote an increase in streamflow. (bottom) The (absolute) climatology of streamflow at Maxau, where the black line is the reference climatology.

absolute streamflow climatology for Maxau, which is dominated by snowmelt. From this plot, it appears that during the period 2002-50 the maximum monthly discharge at Maxau, which occurs in June, does not change or slightly increases (for the A1B scenario). The start of the melting season is slightly shifted to occur earlier in the year. During the second half of the twenty-first century, however, the melting season starts about 6-8 weeks earlier and maximum discharge is significantly lower than during the reference period. In late summer (July to September), therefore, discharge is reduced considerably. The largest difference with the reference period is reached in August and amounts to about $40 \%$ less discharge at Maxau. The A1B scenario shows the most severe decrease in discharge. The earlier snowmelt in combination with increased precipitation in winter and spring (Figs. 10 and 11) causes increased discharge in these seasons. The increase in winter and spring nearly offsets the decrease in summer: annual streamflow slightly $(<10 \%)$ increases for the A2 and B1 scenarios. For the A1B scenario the annual streamflow slightly decreases $(\sim 2 \%)$. The pronounced seasonal cycle that is visible at Maxau also dominates the signal at Lobith, albeit slightly damped. During the period 2052-2100, the maximum decrease in streamflow (in August) is about $30 \%$ for the A1B scenario, which is again the most extreme, whereas the A2 scenario shows the strongest increase in April (also about $30 \%$ ). Similar to Maxau, there is an increase in streamflow during the period 2002-50 compared to the reference period, even in the summer months. In the tributaries, the Ruhr (Hattingen) and the Main (Raunheim), the seasonal cycle is less pronounced. In the Ruhr, streamflow 

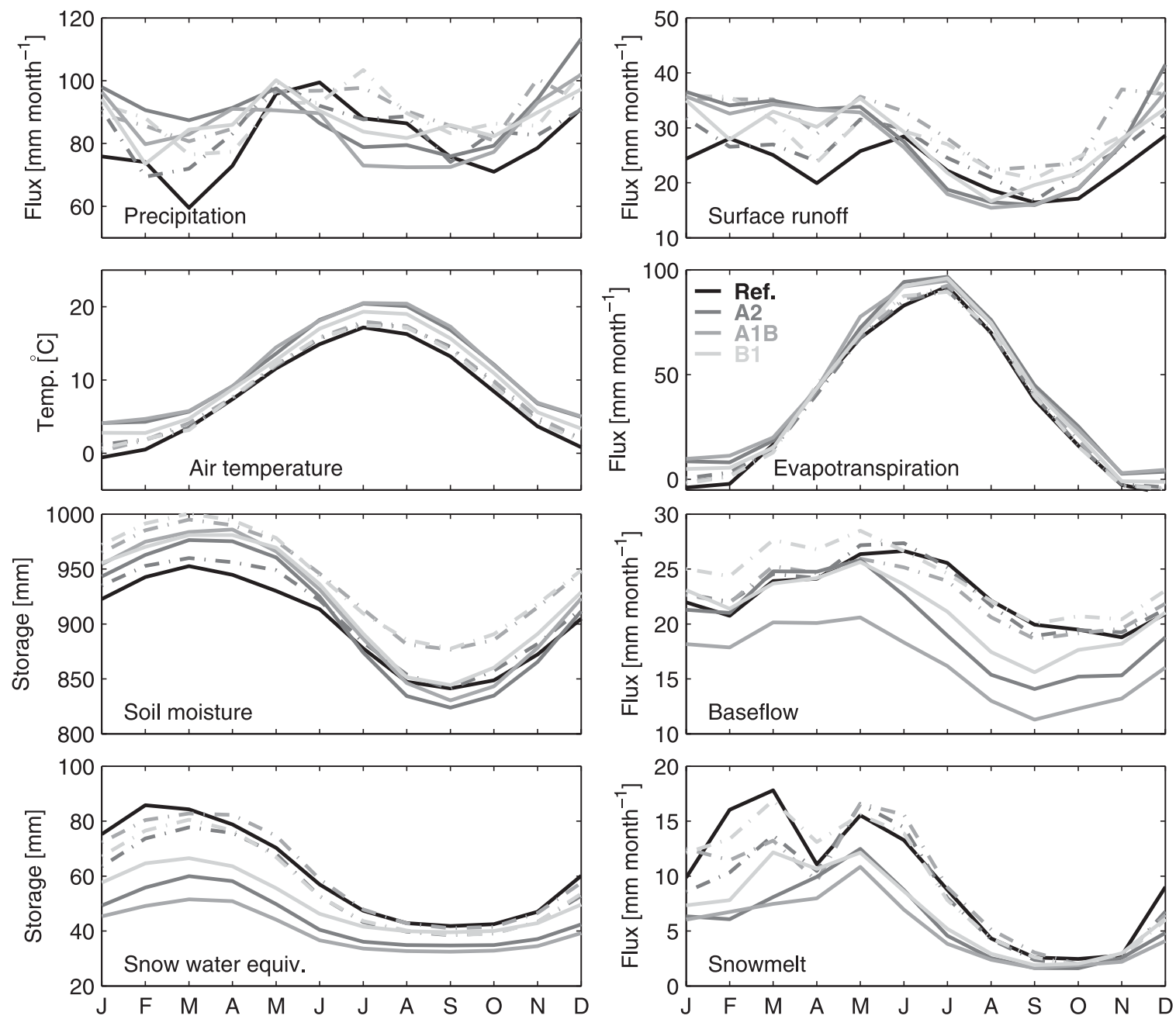

FIG. 10. Climatologies of eight water balance components and air temperature, averaged over the entire basin. The reference period and three climate scenarios (A2, A1B, and B1) are shown for the periods 2002-50 (dash-dotted lines) and 2052-2100 (solid lines).

increases throughout the year with $10 \%-20 \%$ for both the first and second half of the twenty-first century. In the Main, finally, also an overall increase in streamflow can be seen for the period 2002-50. The B1 scenario especially shows a strong increase (up to $30 \%$ ) in late summer. In the period 2052-2100, however, also the Main shows increasing streamflow in winter and spring, except February and March, and decreasing streamflow in summer and autumn. The overall increase in streamflow in the Ruhr and Main subbasins is in accordance with Fig. 6: the northern part of the Rhine basin, including the Main and Ruhr, is dominated by increasing precipitation throughout the year, although very little in summer. The severe decrease in precipitation in the summer season, therefore, only affects the southern tributaries, especially the Neckar and the Alpine part of the Rhine, as can be seen in the lower two panels of Fig. 9 .

\section{c. Water balance components}

Figure 10 shows average monthly values of some of the main water balance terms, averaged over the entire basin. To show the differences in more detail, the differences between the scenarios and the reference period are shown in Fig. 11. In addition, Table 3 shows annual values of all water balance terms. As can be expected, precipitation shows a similar pattern as streamflow (Fig. 9): overall increases during the period 2002-50, and a decrease in the summer season during the period 20522100 with about $15 \%$. This decrease in precipitation is amplified to the $30 \%$ decrease in streamflow (Fig. 9) by increased evapotranspiration. This increases with about $8 \%$ for the A1B and $\mathrm{A} 2$ scenarios during the second half of the century. During the first half, this increase is still relatively modest with annual increases of about $2 \%$. In 

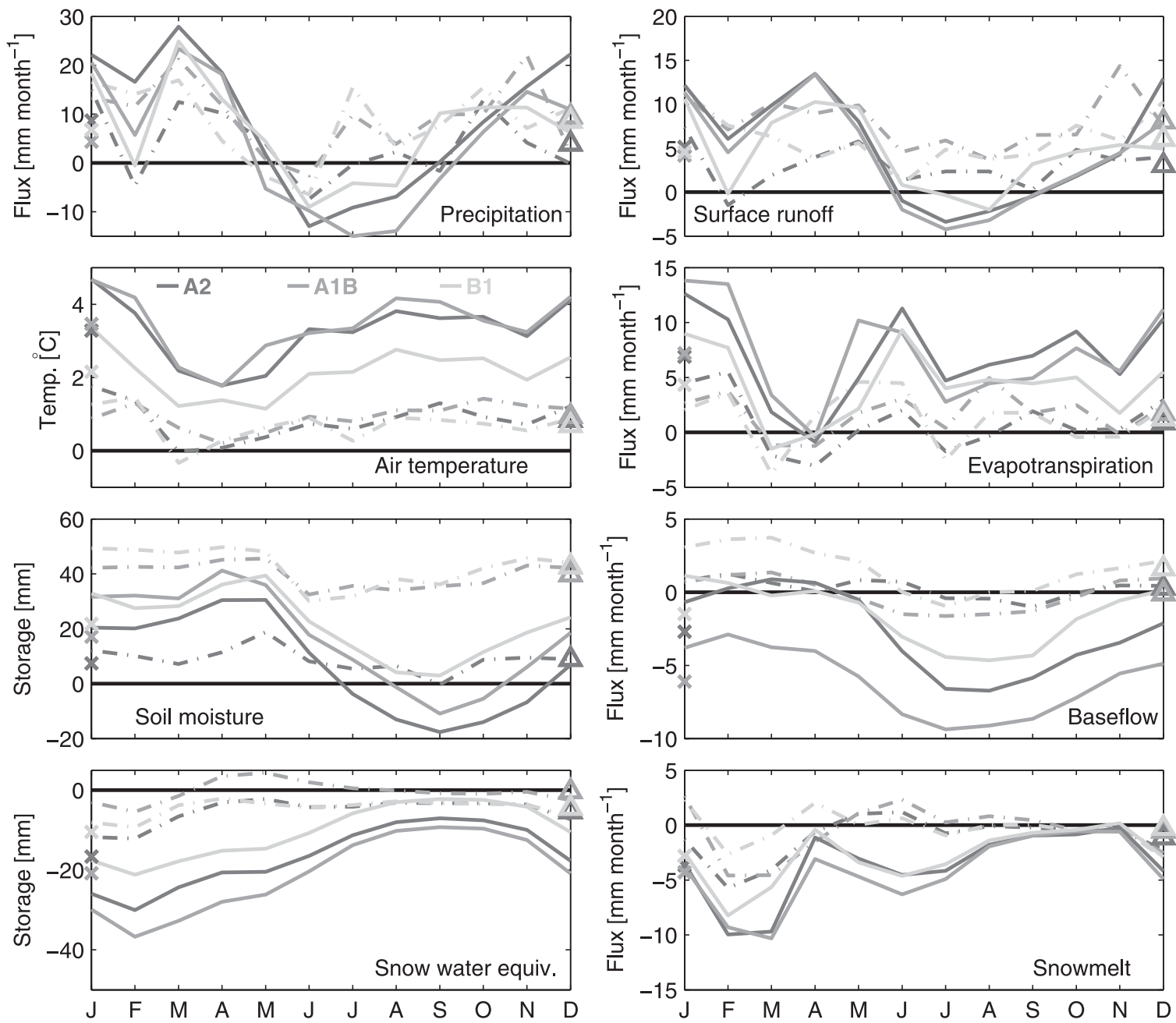

FIG. 11. Climatology differences between the scenarios and the reference period for eight water balance components and temperature, averaged over the entire basin. Positive values denote increases. Differences between the period 2002-50 and the reference period are indicated by dash-dotted lines and triangles (for annual means); differences between the period 2052-2100 and the reference period are indicated by solid lines and crosses (for annual means).

both cases, evapotranspiration changes throughout the year, except for a short period in March and April. This pattern is similar to that of air temperature, indicating that on average evapotranspiration remains mainly energy limited, which is not surprising given the overall increases in streamflow and precipitation. The seasonal effect in precipitation seems to disappear to a large extent. Whereas during the reference period the highest monthly precipitation sums occur in summer and the lowest in March, precipitation is distributed more equally over the months in all scenarios. This causes the large seasonal differences (increase in spring, decrease in summer) that are observed in Fig. 11.

Surface runoff, as expected, closely follows the climatology of precipitation and baseflow illustrates the transition to dryer circumstances during the second half of the century. Whereas there is still an increase in annual values of baseflow during the first half of the century, during the period 2052-2100 baseflow decreases throughout the year and most severely in (late) summer. This is related to the increase in evapotranspiration during the second half of the century, which reduces the amount of water infiltrating and contributing to baseflow. Snowmelt is not a standard output variable of the VIC model. It is, therefore, estimated by taking the daily difference of the snow water equivalent (SWE). If this difference is positive, accumulation has occurred and melt is assumed to be zero. We realize that this assumption is not always valid (melt and accumulation can occur simultaneously), but the resulting melt will be approximately right. Note that in the VIC model snowmelt is added to precipitation before infiltration and runoff 
TABLE 3. Annual values of water balance fluxes $\left(\mathrm{mm} \mathrm{yr}^{-1}\right)$ and storages $(\mathrm{mm})$ for the reference situation and three climate scenarios (A2, A1B, B1) for the first half of the twenty-first century (2002-50) and the second half (2052-2100).

\begin{tabular}{|c|c|c|c|c|c|c|c|}
\hline & \multirow{2}{*}{$\begin{array}{c}1952-2000 \\
\text { Ref }\end{array}$} & \multicolumn{3}{|c|}{$2002-50$} & \multicolumn{3}{|c|}{$2052-2100$} \\
\hline & & A2 & A1B & B1 & A2 & A1B & $\mathrm{B} 1$ \\
\hline Precipitation & 968 & 1015 & 1082 & 1071 & 1073 & 1021 & 1050 \\
\hline Air temperature & 8.06 & 8.89 & 8.99 & 8.75 & 11.34 & 11.52 & 10.21 \\
\hline Evapotranspiration & 411 & 422 & 432 & 426 & 494 & 498 & 463 \\
\hline Interception evaporation & 16.8 & 12.4 & 12.5 & 16.3 & 12.2 & 12.5 & 11.0 \\
\hline Bare soil evaporation & 150 & 153 & 155 & 147 & 174 & 177 & 164 \\
\hline Transpiration & 284 & 289 & 299 & 295 & 327 & 325 & 314 \\
\hline Surface runoff & 277 & 313 & 373 & 349 & 339 & 327 & 332 \\
\hline Baseflow & 271 & 274 & 269 & 290 & 238 & 197 & 253 \\
\hline Soil moisture & 900 & 909 & 940 & 943 & 907 & 917 & 922 \\
\hline Snow water equivalent & 61.1 & 55.7 & 60.7 & 56.6 & 44.5 & 40.3 & 50.6 \\
\hline Snowmelt & 113 & 100 & 107 & 110 & 69 & 62 & 80 \\
\hline
\end{tabular}

are calculated. It is, therefore, included in the baseflow and surface runoff fluxes. For the period 2002-50, snowmelt increases in early summer compared with the reference period. SWE also increases in spring and early summer, but only for the A1B scenario. This is in accordance with higher precipitation during the spring season (Fig. 11), as a portion of this precipitation falls as snow. Because the difference in air temperature is larger for summer than for spring during the period 2002-50, the excess snow from the spring season melts in summer.

The annual values shown in Table 3 further illustrate the changes described above. In all scenarios precipitation increases quite drastically already during the period 2002-50 (on average $88 \mathrm{~mm}$, which is similar to the increase in the period 2052-2100), whereas evapotranspiration increases mainly during the second half of the century. This is correlated with air temperature, which also shows a modest increase during the first half of the century and a significantly larger increase during the second half. This can also be seen in the annual values for snowmelt and SWE, which show a larger decrease during the second half of the century.

\section{d. Extreme streamflow}

While the average changes in streamflow discussed in section $4 \mathrm{~b}$ provide useful information, extreme streamflow events are more relevant from a water management perspective. In this section, both peak flows and low flows are discussed. Figure 12 shows annual maxima as a function of their return times for streamflow at Lobith. The parameters of the generalized extreme value (GEV) distribution are estimated using the maximum likelihood method. To put these results in some perspective, also the annual maxima from the observed record at Lobith [available from the Royal Netherlands Meteorological Institute (KNMI) Web site: http://www.knmi.nl] are shown. For comparison, two different periods from the twentieth century are displayed that each contain 49 yr (1901-49 and 1950-98), similar to the other curves in the graph. For both the periods 2002-50 and 20522100 , annual maxima are higher than the reference situation for all three scenarios at nearly all return periods. During the first half of the century, the A1B and B1 scenarios are both higher than the A2 scenarios, whereas this reversed during the second half. During both periods the most extreme events are simulated under the A1B scenario, with the highest peak reaching nearly $16000 \mathrm{~m}^{3} \mathrm{~s}^{-1}$. The most extreme event in the reference simulation, about $11000 \mathrm{~m}^{3} \mathrm{~s}^{-1}$ (comparable to the near floods in 1993 and 1995, which appear as the most extreme events in the "1950-98" curve), will occur on average every 5-6 yr during both halves of the twentyfirst century for the most extreme scenarios. An event of the magnitude of 1926 (the most extreme event in the "1901-49" curve) would occur every 10-20 yr according to the climate scenarios. During the first half of the century the most extreme events seem to be larger than during the second half of the century, which is also suggested by Fig. 5. In addition, it shows that either the hydrological model or the precipitation in the reference dataset structurally overestimates events with low to medium return periods. For the extreme events, models and observations agree well.

A similar analysis is carried out for streamflow droughts. Several approaches exist to define a drought (e.g., Tallaksen and van Lanen 2004; Fleig et al. 2006). Because not all annual low-flow events reflect a drought, we define a streamflow drought as a cumulative deficit of streamflow below a threshold. At the moment the threshold is exceeded, the event ends (Hisdal et al. 2004). The threshold was selected to be the 75th percentile of streamflow (meaning the streamflow that is equaled or exceeded for $75 \%$ of the time) during the reference period (Hisdal et al. 2004). This value is a compromise 

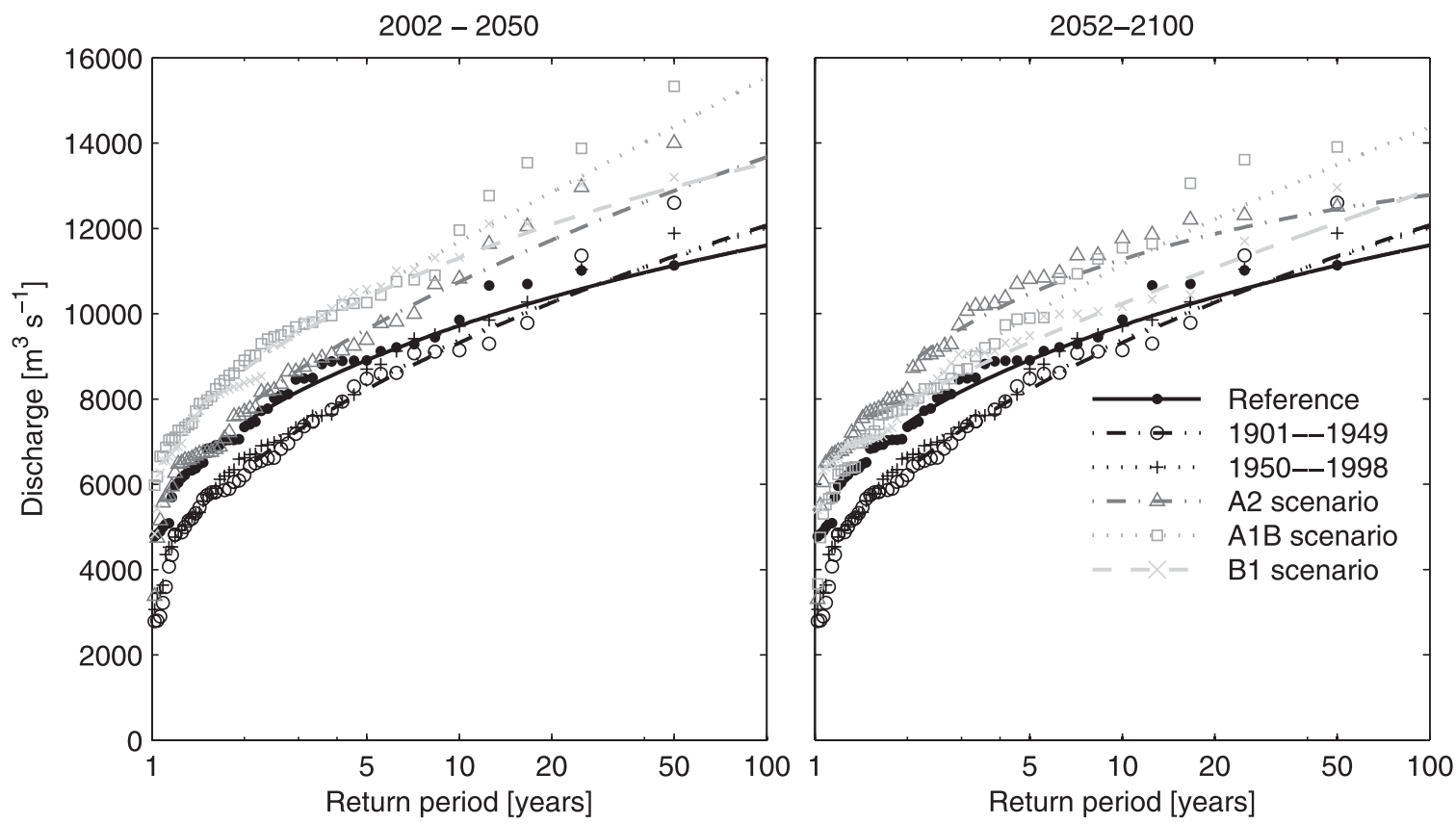

FIG. 12. Annual maximum discharge at Lobith vs its return period for the reference period (1952-2000) and three climate scenarios. Both the periods (left) 2002-50 and (right) 2052-2100 are displayed. A GEV distribution is adjusted to the data. In addition, two periods of $49 \mathrm{yr}$ from the observed record are shown (1901-49 and 1950-98).

between the number of years without any events and the number of multiyear events, both of which can affect the results of the analysis (Fleig et al. 2006). Figure 13 shows the annual maximum deficit volume of such events versus their return periods. A generalized Pareto (GP) distribution is a suitable distribution to model such cumulative deficits (Tallaksen et al. 2004; Fleig et al. 2006). Therefore, such a distribution is adjusted to the data in Fig. 13, again using maximum likelihood estimation. Additional streamflow drought statistics are shown in Table 4. Here, three statistics are selected: the average number of events per year, the average annual maximum duration, and the average annual maximum intensity. The intensity is defined as the deficit volume (of which the annual maxima are plotted in Fig. 13), divided by the duration in seconds. The intensity (shown in $\mathrm{m}^{3} \mathrm{~s}^{-1}$ ) can thus be seen as the average streamflow deficit during the event.

Figure 13 shows that, during the first half of the century, streamflow drought deficits are lower than the reference in all scenarios for small return periods. There are, however, some extreme events that are considerably higher than the extreme events during the reference period, especially in the A2 scenario. For the second half of the century the picture is entirely different: for nearly all return periods and all three scenarios streamflow drought deficits are larger than in the reference simulation. The most extreme streamflow drought deficit in the reference simulation, about $40 \times 10^{8} \mathrm{~m}^{3}$, occurs every 3-10 yr depending on the scenario. The most extreme events during the period 2052-2100 occur in the A1B scenario and have a drought deficit volume that is more than double the volume during the reference period. Table 4 shows the streamflow drought events in more detail. Because statistics are shown for different locations in the basin (Fig. 1), it also shows which regions are most susceptible to streamflow droughts. In Table 4 , it can be seen that there are indeed significant regional differences within the basin. While the overall trend confirms the trends shown in Fig. 13, there are some exceptions. For example, in the Mosel catchment, number, duration, and intensity all keep decreasing during the twenty-first century. This seems in contradiction with Fig. 7. Here it can be seen that a large part of the Mosel catchment experiences a decrease in summer evapotranspiration, supposedly because of water limitation. In winter, however, there is also an increase in precipitation. An explanation for this contradiction is the fact that the winter precipitation rapidly percolates to the groundwater, where the water is out of reach for plants. Soil moisture droughts thus occur because evapotranspiration is water limited. However, the groundwater sustains relatively high baseflow levels, preventing streamflow droughts (Tallaksen and van Lanen 2004).

From Table 4, the Neckar basin appears to be the most susceptible to streamflow droughts: especially for the A1B scenario, the average maximum duration increases from 

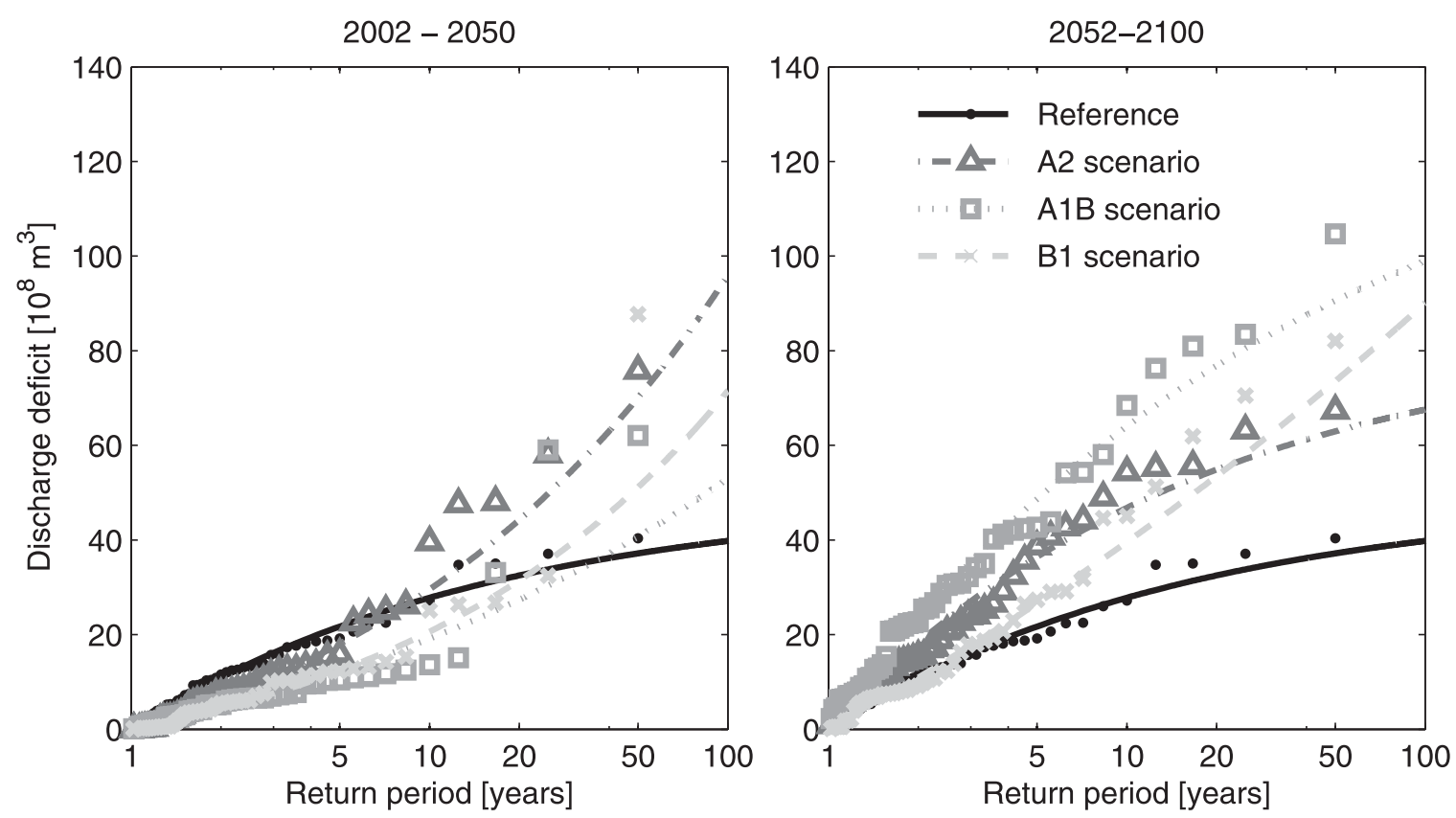

FIG. 13. Annual maximum cumulative deficit of streamflow with respect to a threshold vs its return period for the reference period (1952-2000) and three climate scenarios. The periods (left) 2002-50 and (right) 2052-2100 are displayed. The threshold is selected to be the 75 th percentile at Lobith. A GP distribution is adjusted to the data.

29 to 81 days (the overall highest value) and the intensity rises from 29 to $60 \mathrm{~m}^{3} \mathrm{~s}^{-1}$, which is also the highest value relative to the threshold streamflow (which is only $108 \mathrm{~m}^{3} \mathrm{~s}^{-1}$ ). The A1B scenario shows the highest values of drought statistics for most subbasins and the entire basin, which corresponds to Fig. 13. Figures 6 and 7 explain the fact that the Neckar subbasin appears to be extremely vulnerable to streamflow drought events through the combination of strongly decreasing summer precipitation, only weakly increasing winter precipitation, and increasing summer evapotranspiration. The same holds for the Alpine area, represented by Maxau. Because a large part of the Rhine discharge originates upstream of Maxau, this also has a strong influence at Lobith, the basin outlet.

\section{Discussion}

Data from a single GCM, RCM, and hydrological model were used, whereas ideally one would use an ensemble for each model type. Model comparisons indicate a large range in model projections between GCMs. For example, the Coupled Model Intercomparison Project (CMIP) compared globally averaged air temperatures for the period 1961-90s simulated by 18 GCMs and found a range of more than $4^{\circ} \mathrm{C}$ around the observed $14^{\circ} \mathrm{C}$ (Covey et al. 2003). For precipitation, a similar range was found. Also the projected trend in global temperature structurally differs between GCMs. For example, the GCM used in this study, ECHAM5-MPI-OM, is known to give relatively strong temperature increases in the second half of the twenty-first century. As a model comparison in Adger et al. (2007) shows, ECHAM5-MPI$\mathrm{OM}$ is relatively "cool" compared to the multimodel mean in the first half of the century and relatively warm in the second half. The reason is a relatively high sensitivity of ECHAM5-MPI-OM to aerosol concentrations: in the first half of the century aerosol concentrations are high and their dimming effect is relatively strong. In the second half of the century, the model reacts strongly to the decline of aerosol concentrations, causing a strong temperature increase. This feature partly explains the contrast in our results between the periods 2001-50 and 2051-2100 (relatively wet versus relatively dry) and further illustrates the need for a similar analysis with an ensemble of GCMs. The fact that in CMIP the ECHAM4 model is quite close to observed values for global mean temperature and precipitation (Fig. 1 of Covey et al. 2003) is encouraging. Also, in model comparisons regarding other climate variables, ECHAM is ranked among the best performing GCMs (van Ulden and van Oldenborgh 2006). In a recent model comparison, Reichler and Kim (2008) showed that ECHAM5-MPI-OM (which we use) performs very well compared to most other GCMS in simulating the current climate in terms of many different climate variables. Furthermore, the fact that our results 
TABLE 4. Statistics of streamflow drought events during the reference period and the first and second half of the twenty-first century for the three climate scenarios (A2, A1B, and B1) for seven streamflow gauges in the Rhine basin. For locations and corresponding subbasins see Fig. 1. Three statistics are shown, indicated by S1, S2, and S3. Here S1 is the average number of events (i.e., nonexceedance of the threshold) per year; S2 is the average of annual maximum durations in days; S3 is the average of annual maximum intensities, where the intensity is defined as deficit volume (plotted in Fig. 13) divided by duration, in $\mathrm{m}^{3} \mathrm{~s}^{-1}$. For each station, the threshold value (75th percentile of the reference period) is shown in parentheses.

\begin{tabular}{|c|c|c|c|c|c|c|c|c|c|c|c|c|}
\hline \multirow[b]{2}{*}{ Period } & \multicolumn{3}{|c|}{ Reference } & \multicolumn{3}{|c|}{ A2 scenario } & \multicolumn{3}{|c|}{ A1B scenario } & \multicolumn{3}{|c|}{ B1 scenario } \\
\hline & $\mathrm{S} 1$ & $\mathrm{~S} 2$ & S3 & $\mathrm{S} 1$ & S2 & S3 & $\mathrm{S} 1$ & $\mathrm{~S} 2$ & S3 & $\mathrm{S} 1$ & S2 & S3 \\
\hline \multicolumn{13}{|c|}{ Hattingen $\left(37.8 \mathrm{~m}^{3} \mathrm{~s}^{-1}\right)$} \\
\hline $2002-50$ & & & & 6.5 & 33 & 17.6 & 5.0 & 27 & 15.6 & 4.6 & 26 & 12.9 \\
\hline $2052-2100$ & 5.7 & 33 & 16.8 & 7.1 & 35 & 19.7 & 6.7 & 39 & 19.9 & 6.0 & 33 & 18.9 \\
\hline \multicolumn{13}{|c|}{ Kalkofen $\left(17.0 \mathrm{~m}^{3} \mathrm{~s}^{-1}\right)$} \\
\hline $2002-50$ & & & & 8.1 & 30 & 5.8 & 7.3 & 25 & 5.5 & 6.0 & 22 & 4.6 \\
\hline $2052-2100$ & 7.5 & 33 & 5.6 & 8.7 & 32 & 7.1 & 9.0 & 34 & 7.1 & 7.3 & 28 & 6.2 \\
\hline \multicolumn{13}{|c|}{ Raunheim $\left(92.9 \mathrm{~m}^{3} \mathrm{~s}^{-1}\right)$} \\
\hline $2002-50$ & & & & 5.4 & 31 & 17.7 & 5.0 & 25 & 16.5 & 4.0 & 23 & 14.7 \\
\hline $2052-2100$ & 6.5 & 34 & 22.5 & 6.2 & 37 & 19.2 & 5.7 & 40 & 17.8 & 6.0 & 35 & 17.3 \\
\hline \multicolumn{13}{|c|}{ Cochem $\left(165.9 \mathrm{~m}^{3} \mathrm{~s}^{-1}\right)$} \\
\hline $2002-50$ & & & & 6.1 & 32 & 32.1 & 6.1 & 40 & 38.8 & 5.9 & 26 & 33.5 \\
\hline $2052-2100$ & 6.4 & 37 & 37.9 & 4.2 & 34 & 24.3 & 3.9 & 35 & 22.1 & 4.0 & 23 & 20.4 \\
\hline \multicolumn{13}{|c|}{ Rockenau $\left(107.8 \mathrm{~m}^{3} \mathrm{~s}^{-1}\right)$} \\
\hline $2002-50$ & & 29 & 291 & 5.5 & 26 & 23.5 & 7.4 & 25 & 27.2 & 4.1 & 24 & 21.6 \\
\hline $2052-2100$ & 7.0 & 29 & 29.1 & 9.5 & 44 & 40.0 & 11.8 & 81 & 60.1 & 8.4 & 42 & 36.8 \\
\hline \multicolumn{13}{|c|}{ Maxau $\left(986.9 \mathrm{~m}^{3} \mathrm{~s}^{-1}\right)$} \\
\hline $2002-50$ & & & & 4.1 & 30 & 217 & 4.1 & 20 & 204 & 4.1 & 23 & 173 \\
\hline $2052-2100$ & 4.8 & 33 & 209 & 7.2 & 33 & 334 & 8.7 & 38 & 420 & 5.8 & 28 & 259 \\
\hline \multicolumn{13}{|c|}{ Lobith $\left(1801 \mathrm{~m}^{3} \mathrm{~s}^{-1}\right)$} \\
\hline $2002-50$ & & & & 5.8 & 27 & 424 & 5.4 & 21 & 400 & 5.0 & 21 & 363 \\
\hline $2052-2100$ & 6.8 & 32 & 475 & 7.7 & 38 & 614 & 8.8 & 46 & 722 & 6.7 & 33 & 510 \\
\hline
\end{tabular}

qualitatively confirm results of previous studies for the Rhine basin using other or multiple GCMs suggests that the GCM we used is broadly representative. The range of temperature changes that is projected by GCMs is further extended by the RCMs that are used for downscaling (e.g., van den Hurk et al. 2005; Jacob et al. 2007; Déqué et al. 2007). In addition to the uncertainty in atmospheric models, there is also uncertainty involved in hydrological models and their parameterizations. However, given the fact that each GCM and RCM requires a specific bias correction (associated with different structural model errors), and each combination of a hydrological model with an atmospheric dataset would require a specific calibration, it was not feasible in the present study to use multiple models. This is a common problem in hydrological climate change impact studies: most studies involving a similar model chain as the present study also take into account only one (e.g., Dankers and Feyen 2008; Akhtar et al. 2009) or very few (e.g., de Wit et al. 2007; Booij 2005) GCMs.

The bias correction that was applied to the meteorological data altered the spatial pattern of precipitation and temperature because the correction was applied to each of 134 subbasins for which observations were available. As was noted in section $4 \mathrm{a}$ and can be seen in
Fig. 4, the spatial pattern from the RCM is "drawn" toward that of the observations. In addition, the difference between the reference dataset and the scenarios can be amplified or reduced somewhat because the same exponent [Eq. (1)] is applied to both. When the basinwide spatial average is considered, this effect largely cancels out. This feature, however, is inherent to our correction for the model bias, which can be seasonally and geographically varying (e.g., Christensen et al. 2008; Leander and Buishand 2007). The above should be kept in mind when interpreting the spatial patterns as presented in this paper or comparing them with uncorrected climate scenarios. Furthermore, while we assume that the model biases are similar for the current climate and the changing climate, Christensen et al. (2008) found that this is not always valid and biases tend to grow under warming conditions and depend on the amount of precipitation, suggesting an overestimation of the temperature increase.

Finally, it is important to mention that the presented analysis of hydrological extremes is based on relatively short time series $(3 \times 100 \mathrm{yr})$, whereas the Rhine discharge at Lobith that is relevant for safety purposes has a return period of $1250 \mathrm{yr}$ (de Wit and Buishand 2007). The highest occurring streamflow in this study (about 
$16000 \mathrm{~m}^{3} \mathrm{~s}^{-1}$ ) is associated with much shorter return periods and therefore does not imply that higher values are not possible. Moreover, in this study river hydraulics and flooding are not taken into account, whereas flooding in Germany would have a significant impact on peak discharge at Lobith (de Wit and Buishand 2007).

\section{Conclusions}

The present study differs from previous climate change impact assessments in the Rhine basin regarding the following points: 1) the spatial resolution of the employed climate scenarios is higher, allowing for a detailed spatial analysis of the results and a better representation of extremes; 2) the hydrological model is more physically based; and 3) the entire twenty-first century was investigated as opposed to a time slice of typically $30 \mathrm{yr}$.

As far as streamflow at Lobith is concerned, this study confirms previous climate change impact assessments in the Rhine basin. By the end of the century, average streamflow at basin outlet is projected to increase by about $30 \%$ in winter and spring and to decrease by a similar percentage in summer and autumn. In addition, considerable increases in the frequency and magnitude of both peak flows and streamflow droughts are projected. The majority of this effect originates in the Alpine part of the catchment. It is caused largely by a decrease of the contribution of snowmelt to streamflow and by a shift of the timing of the snowmelt season to earlier in the year.

The high-resolution climate scenarios and the (distributed) hydrological model allow for a detailed analysis of spatial patterns. Results indicate that the projected decrease in summer discharge is concentrated in the southern part of the basin. Over the (relatively small) Black Forest and the Vogues Mountains, however, precipitation increases during the entire year. The northern tributaries, where there is hardly any decrease in summer precipitation, are dominated by wetter conditions throughout the year.

The availability of data for the entire century allows the analysis of trends throughout the century, of which an overview is displayed in Fig. 5. Toward the end of the twenty-first century, a gradually decreasing trend in annual maximum, minimum, and mean streamflow appears. This trend causes an interesting contrast between the first half and the second half of the century. Because precipitation significantly increases in all three scenarios, the first half is dominated by relatively wet conditions. This also shows up in our analysis of peak flows. During the second half of the century, temperature and evapotranspiration increase more drastically than during the first half, causing generally dryer conditions and more extreme droughts. Partly, this contrast originates from our choice of the GCM (see section 5). Ideally, to verify this it would be necessary to use an ensemble of GCMs. The fact that the employed GCM simulates the current climate realistically and its results are broadly comparable to results from other studies, however, suggests that the ECHAM5-MPI-OM model is representative, and results from a multimodel analysis would not be completely different. Nevertheless, it would be very interesting to repeat this analysis with another, or multiple, GCMs.

Acknowledgments. This research was financially supported by the European Commission through the FP6 integrated Project NeWater and the BSIK ACER project of the Dutch Climate Changes Spatial Planning Programme. Rita Lammersen and Hendrik Buiteveld from Rijkwaterstaat Waterdienst, Lelystad, Netherlands, are kindly acknowledged for providing observed streamflow data, and the international Commission for the Hydrology of the Rhine basin (CHR) is acknowledged for making available the observed precipitation and temperature. Finally, we thank the two anonymous reviewers for their helpful and constructive comments.

\section{REFERENCES}

Adger, N., and Coauthors, 2007: Summary for policy makers. Climate Change 2007: Impacts, Adaptation and Vulnerability, M. L. Parry et al., Eds., Cambridge University Press, 7-22.

Akhtar, M., N. Ahmad, and M. J. Booij, 2009: Use of regional climate model simulations as input for hydrological models for the Hindukush-Karakorum-Himalaya region. Hydrol. Earth Syst. Sci., 13, 1075-1089.

Barnett, T. P., J. C. Adam, and D. P. Lettenmaier, 2005: Potential impacts of a warming climate on water availability in snowdominated regions. Nature, 438, 303-309, doi:10.1038/ nature 04141.

Booij, M. J., 2005: Impact of climate change on river flooding assessed with different spatial model resolutions. J. Hydrol., 303, 176-198.

Christensen, J. H., T. R. Carter, M. Rummukainen, and G. Amanatidis, 2007: Evaluating the performance and utility of regional climate models: The PRUDENCE project. Climatic Change, 81, 1-6, doi:10.1007/s10584-006-9211-6.

— , F. Boberg, O. B. Christensen, and P. Lucas-Picher, 2008: On the need for bias correction of regional climate change projections of temperature and precipitation. Geophys. Res. Lett., 35, L20709, doi:10.1029/2008GL035694.

Covey, C., K. M. AchutaRao, U. Cubasch, P. Jones, S. J. Lambert, M. E. Mann, T. J. Philips, and K. E. Taylor, 2003: An overview of results from the Coupled Model Intercomparison Project. Global Planet. Change, 37, 103-133.

Dankers, R., and L. Feyen, 2008: Climate change impact on flood hazard in Europe: An assessment based on high-resolution climate simulations. J. Geophys. Res., 113, D19105, doi:10.1029/ 2007JD009719.

Déqué, M., and Coauthors, 2007: An intercomparison of regional climate simulations for Europe: Assessing uncertainties in 
model projections. Climatic Change, 81, 53-70, doi:10.1007/ S10584-006-9228-x.

de Wit, M. J. M., and T. A. Buishand, 2007: Generator of rainfall and discharge extremes (GRADE) for the Rhine and Meuse basins. Tech. Rep., Rijkswaterstaat RIZA Rep. 2007.027/ KNMI publication 218, Lelystad, Netherlands, 77 pp.

—, B. van den Hurk, P. M. M. Warmerdam, P. J. J. F. Torfs, E. Roulin, and W. P. A. van Deursen, 2007: Impact of climate change on low-flows in the river Meuse. Climatic Change, 82, 351-372, doi:10.1007/S10584-006-9195-2.

Fleig, A. K., L. M. Tallaksen, H. Hisdal, and S. Demuth, 2006: A global evaluation of streamflow drought characteristics. Hydrol. Earth Syst. Sci., 10, 535-552.

Graham, L. P., S. Hagemann, S. Jaun, and M. Beniston, 2007: On interpreting hydrological change from regional climate models. Climatic Change, 81, 97-122, doi:10.1007/s10584-006-9217-0.

Hagemann, S., H. Göttel, D. Jacob, P. Lorenz, and E. Roeckner, 2009: Improved regional scale processes reflected in projected hydrological changes over large European catchments. Climate Dyn., 32, 767-781, doi:10.1007/s00382-008-0403-9.

Hamlet, A. F., P. W. Mote, M. P. Clark, and D. P. Lettenmaier, 2007: Twentieth-century trends in runoff, evapotranspiration and soil moisture in the western United States. J. Climate, 20, 1468-1486.

Hay, L. E., M. P. Clark, R. L. Wilby, W. J. Gutowski Jr., G. H. Leavesly, Z. Pan, R. W. Arritt, and E. S. Takle, 2002: Use of regional climate model output for hydrologic simulations. J. Hydrometeor., 3, 571-590.

Hisdal, H., L. M. Tallaksen, B. Clausen, E. Peters, and A. Gustard, 2004: Hydrological drought characteristics. Hydrological Drought: Processes and Estimation Methods for Streamflow and Groundwater, Elsevier, 139-198.

Hurkmans, R. T. W. L., H. de Moel, J. C. J. H. Aerts, and P. A. Troch, 2008: Water balance versus land surface model in the simulation of Rhine river discharges. Water Resour. Res., 44, W01418, doi:10.1029/2007WR006168.

—, W. Terink, R. Uijlenhoet, E. J. Moors, P. A. Troch, and P. H. Verburg, 2009: Effects of land use changes on streamflow generation in the Rhine basin. Water Resour. Res., 45, W06405, doi:10.1029/2008WR007574.

Jacob, D., 2001: A note to the simulation of the annual and interannual variability of the water budget over the Baltic Sea drainage basin. Meteor. Atmos. Phys., 77, 61-73.

- and Coauthors, 2007: An inter-comparison of regional climate models for Europe: Model performance in present-day climate. Climatic Change, 81, 31-52, doi:10.1007/S10584-006-9213-4.

—, H. Göttel, S. Kotlarski, P. Lorenz, and K. Sieck, 2008: Klimaauswirkungen und Anpassung in Deutschland-Phase 1: Erstellung regionaler Klimaszenarien für Deutschland (Climate impact and adaptation in Germany-Phase 1: Production of regional climatic scenarios for Germany). Research Rep. 20441138 UBA-FB 000969, Final Rep. to the UFO plan project, Federal Office for Environment Protection, Dessau, Germany, $154 \mathrm{pp}$

Kleinn, J., C. Frei, J. Gurtz, D. Lüthi, P. L. Vidale, and C. Schär, 2005: Hydrologic simulations in the Rhine basin driven by a regional climate model. J. Geophys. Res., 110, D04102, doi:10.1029/2004JD005143.

Kwadijk, J., and H. Middelkoop, 1994: Estimation of impact of climate change on the peak discharge probability of the river Rhine. Climatic Change, 27, 199-224.

— and J. Rotmans, 1995: The impact of climate change on the river Rhine: A scenario study. Climatic Change, 30, 397-425.
Leander, R., and T. A. Buishand, 2007: Resampling of regional climate model output for the simulation of extreme river flows. J. Hydrol., 332, 487-496, doi:10.1016/j.jhydrol.2006.08.006.

Lenderink, G., T. A. Buishand, and W. P. van Deursen, 2007: Estimates of future discharges of the river Rhine using two scenario methodologies: Direct versus delta approach. Hydrol. Earth Syst. Sci., 11, 1145-1159.

Liang, X., D. P. Lettenmaier, E. F. Wood, and S. J. Burges, 1994: A simple hydrologically based model of land surface water and energy fluxes for general circulation models. J. Geophys. Res., 99 (D7), 14 415-14 458.

— , and Coauthors, 1998: The Project for Intercomparison of Land-surface Parameterization Schemes (PILPS) phase 2(c) Red-Arkansas River basin experiment: 2. Spatial and temporal analysis of energy fluxes. Global Planet. Change, 19, 137-159, doi:10.1016/S0921-8181(98)00045-9.

Lohmann, D., R. Nolte-Holube, and E. Raschke, 1996: A largescale horizontal routing model to be coupled to land surface parameterization schemes. Tellus, 48A, 708-721.

_ E. Raschke, B. Nijssen, and D. P. Lettenmaier, 1998a: Regional scale hydrology: I. Application of the VIC-2L model coupled to a routing model. Hydrol. Sci. J., 43, 131-141.

$-, \ldots, \ldots$, and $—, 1998$ b: Regional scale hydrology: II. Application of the VIC-2L model to the Weser River, Germany. Hydrol. Sci. J., 43, 143-158.

- , and Coauthors, 1998c: The Project for Intercomparison of Land-surface Parameterization Schemes (PILPS) phase 2(c) Red-Arkansas River basin experiment: 3. Spatial and temporal analysis of water fluxes. Global Planet. Change, 19, 161-179.

Matheussen, B., R. L. Kirschbaum, I. A. Goodman, G. M. O’Donnell, and D. P. Lettenmaier, 2000: Effects of land cover change on streamflow in the interior Columbia River basin (U.S.A. and Canada). Hydrol. Processes, 14, 867-885.

Middelkoop, H., and Coauthors, 2001: Impact of climate change on hydrological regimes and water resources management in the Rhine basin. Climatic Change, 49, 105-128.

Monteith, J. L., 1965: Evaporation and environment. Proceedings of the 19th Symposium of the Society for Experimental Biology, Cambridge University Press, 205-233.

Mücher, S., K. Steinnocher, J.-L. Champeaux, S. Griguolo, K. Wester, C. Heunks, and V. van Katwijk, 2000: Establishment of a 1-km Pan-European Land Cover database for environmental monitoring. Proceedings of the Geoinformation for All XIXth Congress of the International Society for Photogrammetry and Remote Sensing (ISPRS), K. J. Beek and M. Molenaar, Eds., International Archives of Photogrammetry and Remote Sensing, Vol. 33, GITC, 702-709.

Nakićenović, N., and R. Swart, Eds., 2000: Special Report on Emissions Scenarios. Cambridge University Press, 612 pp. [Available online at http://www.grida.no/publications/other/ ipcc_sr/?src=/climate/ipcc/emission/index.htm.]

Nash, J. E., and I. V. Sutcliffe, 1970: River flow forecasting through conceptual models. Part I-A discussion of principles. J. Hydrol., 10, 282-290.

Nelder, J. A., and R. Mead, 1965: A simplex method for function minimalization. Comput. J., 7, 308-313.

Penman, H. L., 1948: Natural evaporation from open water, bare soil and grass. Proc. Roy. Soc. London, A193, 120-146.

Pfister, L., J. Kwadijk, A. Musy, A. Bronstert, and L. Hoffmann, 2004: Climate change, land use change and runoff prediction in the Rhine-Meuse basins. River Res. Appl., 20, 229-241, doi:10.1002/rra/775. 
Pitman, A. J., and Coauthors, 1999: Key results and implications from Phase 1(c) of the Project for Intercomparison of Land-surface Parameterization Schemes. Climate Dyn., 15, 673-684.

Reichler, T., and J. Kim, 2008: How well do coupled models simulate today's climate? Bull. Amer. Meteor. Soc., 89, 303-311.

Reynolds, C. A., T. J. Jackson, and W. J. Rawls, 2000: Estimating water-holding capacities by linking the Food and Agriculture Organization soil map of the world with global pedon databases and continuous pedotransfer functions. Water Resour Res., 36, 3653-3662.

Shabalova, M. V., W. P. A. van Deursen, and T. A. Buishand, 2003: Assessing future discharge of the river Rhine using regional climate model integrations and a hydrological model. Climate Res., 23, 233-246.

Sprokkereef, E., 2001: Eine hydrologische Datenbank für das Rheingebiet (A hydrological database for the Rhine catchment). International Commission on Hydrology of the Rhine Basin (CHR) Rep., 22 pp.

Tallaksen, L. M., and H. A. J. van Lanen, Eds., 2004: Hydrological Drought: Processes and Estimation Methods for Streamflow and Groundwater. Developments in Water Science, Vol. 48, Elsevier, 579 pp.
- - H. Madsen, and H. Hisdal, 2004: Frequency analysis. Hydrological Drought: Processes and Estimation Methods for Streamflow and Groundwater, L. M. Tallakesen and H. A. J. van Lanen, Eds., Developments in Water Science, Vol. 48, Elsevier, 199271.

Terink, W., R. T. W. L. Hurkmans, R. Uijlenhoet, P. M. M. Warmerdam, and P. J. J. F. Torfs, 2008: Bias correction of temperature and precipitation data for regional climate model application to the Rhine basin. Tech. Rep., Hydrology and Quantitative Water Management group, Wageningen University, Wageningen, Netherlands, $42 \mathrm{pp}$.

Trenberth, K. E., A. Dai, R. M. Rasmussen, and D. B. Parsons, 2003: The changing character of precipitation. Bull. Amer. Meteor. Soc., 84, 1205-1217.

van den Hurk, B., and Coauthors, 2005: Soil control on runoff response to climate change in regional climate model simulations. J. Climate, 18, 3536-3551.

van Ulden, A. P., and G. J. van Oldenborgh, 2006: Large-scale atmospheric circulation biases and changes in global climate model simulations and their importance for climate change in Central Europe. Atmos. Chem. Phys., 6, 863-881.

Zierl, B., and H. Bugmann, 2005: Global change impacts on hydrological processes in Alpine catchments. Water Resour. Res., 41, W02028, doi:10.1029/2004WR003447. 
Copyright of Journal of Climate is the property of American Meteorological Society and its content may not be copied or emailed to multiple sites or posted to a listserv without the copyright holder's express written permission. However, users may print, download, or email articles for individual use. 